\title{
Solving Recent Challenges for Wrought Ni-Base Superalloys
}

\author{
M.C. HARDY, M. DETROIS, E.T. MCDEVITT, C. ARGYRAKIS, V. SARAF, \\ P.D. JABLONSKI, J.A. HAWK, R.C. BUCKINGHAM, H.S. KITAGUCHI, and S. TIN
}

This paper reviews the status of technology in design and manufacture of new wrought polycrystalline Ni-base superalloys for critical engineering applications. There is a strong motivation to develop new alloys that are capable of operating at higher temperatures to realize improvements in thermal efficiency, which are necessary to achieve environmental targets for reduced emissions of harmful green-house gases. From the aerospace sector, the development of new powder metallurgy and ingot metallurgy alloys is discussed for disk rotor and static applications. New compositions for powder metallurgy contain about 50 to 55 pct of gamma prime $\left(\gamma^{\prime}\right)$ strengthening precipitates to ensure components operate successfully at temperatures up to $788^{\circ} \mathrm{C}\left(1450{ }^{\circ} \mathrm{F}\right)$. In contrast, new compositions for ingot metallurgy aim to occupy a design space in temperature capability between Alloy 718 and current powder alloys that are in-service, and show levels of $\gamma^{\prime}$ of about 30 to 44 pct. The focus in developing these alloys was design for manufacturability. To complement the aerospace developments, a review of work to understand the suitability of candidate alloys for multiple applications in Advanced-Ultra Supercritical (AUSC) power plants has been undertaken by Detrois, Jablonski, and Hawk from the National Energy Technology Laboratory. In these power plants, steam temperatures are required to reach $700{ }^{\circ} \mathrm{C}$ to $760{ }^{\circ} \mathrm{C}$. The common thread is to develop alloys that demonstrate a combination of high-temperature properties, which are reliant on both the alloy composition and microstructure and can be produced readily at the right price. For the AUSC applications, the emphasis is on high-temperature strength, long-term creep life, phase stability, oxidation resistance, and robust welding for fabrications. Whereas for powder disk rotors in aircraft engines, the priority is enhanced resistance to time-dependent crack growth, phase stability, and resistance to environmental damage, while extending the current strength levels, which are shown by existing alloys, to higher temperatures.

https://doi.org/10.1007/s11661-020-05773-6

(C) The Minerals, Metals \& Materials Society and ASM International 2020

M.C. HARDY, C. ARGYRAKIS and R. C. BUCKINGHAM are with the Rolls-Royce plc, PO Box 31, Derby, DE24 8BJ, UK. Contact e-mail: mark.hardy@rolls-royce.com. M. DETROIS is with the U.S. Department of Energy, National Energy Technology Laboratory, 1450 Queen Ave., SW, Albany, OR 97321, USA and LRST, 1450 Queen Ave. SW, Albany, OR 97321, USA. E. T. MCDEVITT is with the Allegheny Technologies Incorporated Specialty Materials, 2020 Ashcraft Avenue, PO Box 5030, Monroe, NC 28111, USA. V. SARAF is with the Allegheny Technologies Incorporated Forged Products Cudahy, PO Box 8902, 5481 S. Packard Avenue, Cudahy, WI 53110, USA. P. D. JABLONSKI and J. A. HAWK are with the U.S. Department of Energy, National Energy Technology Laboratory, 1450 Queen Ave., SW. H. S. KITAGUCHI is with the School of Metallurgy and Materials, University of Birmingham, Birmingham, B15 2TT, UK. S. TIN is with the Department of Mechanical, Materials and Aerospace Eng., Illinois Institute of Technology, 10 West 32nd Street, Chicago, IL 60616, USA

Manuscript submitted December 9, 2019.

Article published online May 5, 2020

\section{DEVELOPING ALLOY COMPOSITIONS FOR FUTURE HIGH-TEMPERATURE DISK ROTORS}

\section{A. Introduction}

AIRCRAFT engines and cycles are continuously evolving to provide improved efficiencies for reducing fuel consumption and emissions. ${ }^{[1,2]}$ However, while propulsive and aerodynamic optimizations of aircraft engines are possible, the increased demands upon superalloys (that are used in the hot section parts) limit the thermal efficiency improvements that can be achieved. Higher engine bypass ratios have resulted in smaller engine core sizes that experience increased temperatures and stresses, which pose a complex set of seemingly conflicting properties for the materials considered for safety-critical disk rotor applications. 
New materials with higher strength levels are needed in reducing the size and weight of components and to allow faster shaft speeds. While this necessitates the development of compositions with increased amounts of the gamma prime $\left(\gamma^{\prime}\right)$ phase, ${ }^{[3]}$ further optimization is possible by using a fine grain size. Yet such grain structures produce less appealing time-dependent crack growth behavior, ${ }^{[4]}$ which may limit the design life of the component or the interval between inspections. This is more relevant in today's engines as high climb rates are increasingly required by commercial airlines to move aircraft more quickly to altitude, to reduce fuel burn, and to move the aircraft away from busy air spaces around airports. ${ }^{[5]}$ Therefore, acceptable strength is required from coarse grain microstructures, which demands effective precipitation strengthening from alloy design and control of grain size in near net-shaped forgings that are often complex as they include material for drive arms or shafts.

Inevitably, this is only possible using powder metallurgy to minimize elemental segregation to length scales of a micron $(\mu \mathrm{m})$ or less for these complex, multi-component alloys with high levels of reactive elements (Al, Ti, Ta etc.). ${ }^{[6-8]}$ Subsequent hot deformation of consolidated powder compacts produces billet material with extremely fine grains, which enables superplastic flow of the work piece during isothermal forging at high temperatures and low strain rates, to make the desired near net disk shapes. ${ }^{[6-8]}$ A uniform average grain size of 20 to $40 \mu \mathrm{m}$ can then be created by super-solvus solution heat treatment. This microstructure produces an ideal balance in material properties between tensile strength and resistance to time-dependent crack growth. Otherwise, optimization of strength in the bore or hub of the disk and resistance to time-dependent crack growth and creep in the rim and diaphragm can be achieved by producing dual microstructure forgings, albeit with greater design and manufacturing complexity and cost. $^{[4]}$ These latter considerations have slowed down the introduction of this technology in civil aircraft engines despite successful demonstration of capable manufacturing processes. However, it is understood that dual microstructure IN100 disks are used in F119 military engines. ${ }^{[9]}$

The following sections discuss approaches to achieve the required levels of (i) yield strength and creep resistance through alloy composition and microstructure, (ii) resistance to time-dependent crack growth through optimisation of microstructure, and (iii) phase stability and environmental resistance in nickel base alloys that are designed for disk rotor applications.

\section{B. Predicting Yield Strength}

There are useful models that predict yield strength $^{[10-14]}$ from precipitation hardening, which produces improvements in strength in nickel-based superalloys by resisting the penetration of dislocations through $\gamma^{\prime}$ particles as a result of fault energies from anti-phase boundaries and stacking faults. Such models correlate the critical resolved shear stress or flow stress of the alloy with the volume fraction and size of $\gamma^{\prime}$ particles, and the anti-phase boundary (APB) energy that is produced from pairwise penetration and cutting of dislocations through $\gamma^{\prime}$ particles. Crudden et al. ${ }^{[13]}$ have subsequently showed that the composition of the $\gamma^{\prime}$ particles, i.e., the concentration of $\mathrm{Ti}, \mathrm{Ta}$, and $\mathrm{Nb}$ atoms that replace $\mathrm{Al}$ atoms, has a profound effect on the APB energy and therefore yield stress. This body of work enables alloys to be designed that have higher predicted yield strengths than the predicted values for established compositions, for which there are extensive databases. In practice, other factors will limit the volume fraction of $\gamma^{\prime}$ and the amount of $\mathrm{Al}, \mathrm{Ti}, \mathrm{Nb}$, and $\mathrm{Ta}$ that can be added to alloys to improve strength. For instance, increasing the volume fraction of $\gamma^{\prime}$ will increase the degree of difficulty in manufacturing billet, forgings, and finished disk rotors and assemblies. It will also have a detrimental effect on the resistance to time-dependent crack growth, which will be discussed later. Further additions of $\mathrm{Al}$ and $\mathrm{Ti}$, in particular, can raise the $\gamma^{\prime}$ solvus temperature $\left(T_{\text {solvus }}\right)$ sufficiently $\left(>1180{ }^{\circ} \mathrm{C}\right)$ so that incipient melting can occur at grain boundaries during super-solvus solution heat treatment. The latter is necessary for growing the size of grains to optimize high-temperature properties. This is a concern as the temperature for incipient melting is reduced in alloys with high levels of $\mathrm{B}$ ( $>0.1$ at. pct).

Models for predicting yield stress $\left(\sigma_{y}\right)$ from precipitation hardening are more useful if they include terms for grain size and the size of secondary $\gamma^{\prime}$ particles, i.e., those produced from quenching after solution heat treatment. In Figure 1, predicted values of yield stress from the model proposed by Parthasarathy et al. ${ }^{[11]}$ are compared with measured 0.2 pct proof stress data for the alloys in Table I. The model is based on the equation below:

$$
\begin{aligned}
\sigma_{y}= & \left(1-f_{\gamma^{\prime}}\right)\left\langle M(\mathrm{CRSS})+\frac{k_{\left(\gamma+\gamma^{\prime}\right)}}{\sqrt{d_{\left(\gamma+\gamma^{\prime}\right)}}}\right\rangle \\
& +f_{\gamma}^{\prime}\left\{M * \tau_{\gamma^{\prime}}+\frac{k_{\gamma^{\prime}}}{\sqrt{d_{\gamma^{\prime}}}}\right\},
\end{aligned}
$$

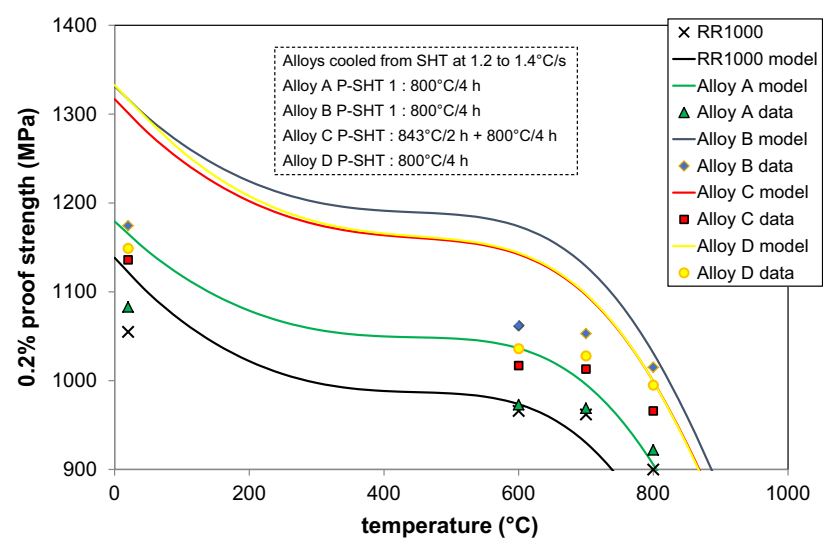

Fig. 1-Actual and predicted yield stress values for RR1000 and the development alloys in Table I. Details of material manufacturing and testing are provided in Ref. 18. 
Table I. Nominal Composition of Development Alloys and RR1000

\begin{tabular}{|c|c|c|c|c|c|c|c|c|c|c|c|c|c|c|c|}
\hline Atomic Percent & $\mathrm{Ni}$ & Co & $\mathrm{Cr}$ & Mo & $\mathrm{W}$ & $\mathrm{Fe}$ & $\mathrm{Mn}$ & $\mathrm{Al}$ & $\mathrm{Ti}$ & $\mathrm{Ta}$ & $\mathrm{Nb}$ & $\mathrm{Hf}$ & B & $\mathrm{C}$ & $\mathrm{Zr}$ \\
\hline RR1000 & Bal. & 17.9 & 16.5 & 3.0 & 0 & 0 & 0 & 6.4 & 4.3 & 0.6 & 0 & 0.16 & 0.08 & 0.13 & 0.03 \\
\hline Alloy A & Bal. & 23.0 & 15.1 & 1.8 & 0.5 & 0 & 0 & 6.3 & 4.8 & 1.2 & 0 & 0 & 0.15 & 0.14 & 0.05 \\
\hline Alloy B & Bal. & 23.0 & 15.1 & 1.8 & 0.5 & 0 & 0 & 6.3 & 4.8 & 1.2 & 1.0 & 0 & 0.15 & 0.14 & 0.05 \\
\hline Alloy C & Bal. & 23.0 & 14.8 & 1.8 & 0.6 & 0.9 & 0.6 & 6.5 & 4.8 & 1.2 & 0.6 & 0 & 0.15 & 0.13 & 0.06 \\
\hline Alloy D & Bal. & 26.0 & 15.0 & 2.0 & 1.0 & 0 & 0 & 6.3 & 5.5 & 0.8 & 0.2 & 0 & 0.14 & 0.14 & 0.04 \\
\hline
\end{tabular}

where $f_{\gamma^{\prime}}$ is the volume fraction of $\gamma^{\prime}$ particles, CRSS is the critical resolved shear stress, $M$ is the Taylor factor for polycrystals, $d$ is grain size, $k$ is the Hall-Petch coefficient for $\gamma$ and $\gamma^{\prime}$ phases, and $\tau_{\gamma^{\prime}}$ is the friction stress that opposes dislocation motion from grain boundary precipitated $\gamma^{\prime}$ particles. Further details of the model can be found in Appendix.

As shown in Figure 1, the model correctly predicts the superiority of Alloys B, C, and D over A and RR1000 but the absolute values of the predictions are higher than the measured ones. The details for material manufacture and testing are provided elsewhere. ${ }^{[18]} \mathrm{It}$ is understood that improved values of yield stress are due to the higher volume fraction of $\gamma^{\prime}$ and the addition of $\mathrm{Nb}$, which increases in APB energy. The predicted values of yield stress are particularly sensitive to the APB energy, the $\gamma$ grain size, the volume fraction and size of secondary $\gamma^{\prime}$ precipitates, and the volume fraction of tertiary $\gamma^{\prime}$ precipitates. Measured compositions, grain size, and precipitate values were used in calculating the predicted curves in Figure 1. The APB energy pre-exponent term $\Gamma_{o}$ (Eq. (3) in Appendix) for each alloy was calculated from the method proposed by Crudden et al., ${ }^{[13]}$ using first principle density functional theory (DFT) calculations for ternary systems comprising of $\mathrm{Ni}_{0.75} \mathrm{Al}_{0.125} \mathrm{X}_{0.125}$ and $\mathrm{Ni}_{3} \mathrm{Al}_{0.5} \mathrm{X}_{0.5}$ where $\mathrm{X}$ is an alternative $\gamma^{\prime}$ former element such as $\mathrm{Ti}$, Ta, $\mathrm{Nb}$, or W. In an earlier publication, ${ }^{[18]}$ the model was fitted to measured yield stress values at room temperature by modifying APB energy, which is calculated at zero Kelvin.

\section{Controlling the Grain Size of Coarse Grain Microstructures}

As indicated earlier, a narrow range of grain size is desired in large complex forgings after solution heat treatment above the $T_{\text {solvus. }}$. Such forgings often show significant variations in forging strain due to changes in geometry, notably for drive arms. There are many factors that determine the final grain size, not least the size of grains in the billet material or forging stock. It is critical for isothermal forging that grains in billet material are extremely fine. This is possible as large (1 to $5 \mu \mathrm{m}$ ), predominantly incoherent primary $\gamma^{\prime}$ precipitates pin grain boundaries. They precipitate preferentially at grain boundaries as a result of incomplete dynamic or meta-dynamic recrystallization of $\gamma$ grains during relatively high strain rate deformation on compacted powder at temperatures below $T_{\text {solvus. }}{ }^{[19]}$ In addition to billet grain size, it is necessary that forging temperatures (below the $T_{\text {solvus }}$ ) and strain rates are deployed that promote super plastic forming as a result of grain boundary sliding and recrystallization. As a general rule, the appropriate forging conditions are those that give rise to a strain rate sensitivity index $\mathrm{m}$ greater than 0.3 in the equation below, which correlates flow stress $(\sigma)$ as a function of strain rate $(d \varepsilon / d t)$, in which $K$ is a material constant. ${ }^{[20]}$

$$
\sigma=K\left(\frac{d \varepsilon}{d t}\right)^{m}
$$

This can be determined by generating flow stress data from hot compression tests on billet material to understand the effects of temperature and strain rate.

In spite of these measures to control grain size, isolated areas of large visible grains can occur in some forgings, in areas that receive low forging strains and specific forging conditions, in which the higher end of forging strain rates are imposed during part of the forging process. This results in a bimodal grain size distribution. The phenomenon in powder Ni disk alloys was initially described as abnormal ${ }^{[21]}$ or critical grain growth. ${ }^{[2]}$. In both cases, the unwanted grain growth was attributed to sub-solvus isothermal forging at strain rates near the transition between super plastic (stage II) flow and power-law creep (stage III) flow. The latter occurs from glide and climb of dislocation within $\gamma$ grains. In these and other studies, ${ }^{[23-26]}$ grain growth behavior has been understood by conducting hot compression or tensile tests on small laboratory test pieces. These, in combination with computer-based finite element software have enabled the results of laboratory experiments to be used to predict the grain growth behavior in full-scale forgings. However, care needs to be taken to ensure that such experiments are representative of much larger forgings. For example, the same rates of heating that are encountered in forgings should also be applied to small laboratory samples. This is important as work by Parr et al. ${ }^{[27]}$ has shown that for low forging strains, a longer heating time (55 to 93 minutes) from $1050{ }^{\circ} \mathrm{C}$ to the super-solvus heat treatment temperature of $1170{ }^{\circ} \mathrm{C}$ increased the grain size of isothermally forged RR1000, particularly the as large as (ALA) grain size. Nevertheless, compression tests are useful as they allow microstructure to be examined after or during each step of the forging and heat treatment processes using electron microscopy and electron backscattered diffraction (EBSD). The latter is 
particularly informative as it can detect differences in grain to grain orientation or differences in orientation within grains. ${ }^{[28]}$ These are a measure of stored energy and indicate differences in stored energy within and between grains, which in turn provides information about the state of recrystallization. ${ }^{[26]}$ Research has been conducted to isolate the forging and heat treatment parameters that contribute to the nucleation and growth of isolated large grains.

Attention has been given to the role of primary $\gamma^{\prime}$ and other pinning particles such as MC carbides on grain size. Figure 2 from Parr et al. ${ }^{[27]}$ clearly shows that the grain boundary of the abnormally large grain passed through many primary $\gamma^{\prime}$ particles. This suggests that the Zener pinning pressure from primary $\gamma^{\prime}$ particles is not effective in stopping the growth of some grains. However, as Smith Zener pinning pressure $\left(P_{\mathrm{z}}\right)$ increases with the volume fraction $\left(f_{v}\right)$ of small particles that have a radius $r$, as in Eq. [3], it has been proposed that a reduced average grain size can be produced from a higher number of small particles,

$$
P_{\mathrm{Z}}=\frac{3 f_{v} E}{2 r}
$$

where $E$ is the matrix-particle interface energy. ${ }^{[29]}$ Above $T_{\text {solvus }}$, primary $\mathrm{MC}$ carbide and oxide particles remain in the microstructure in prior particle boundary networks. These potentially provide further pinning particles. Payton's work on René 88DT ${ }^{[30]}$ confirms this beautifully, although the evidence suggests that there was little or no effect of increased C content on the ALA grain size.

After many detailed EBSD examinations, Bozzolo et al. ${ }^{[26,31]}$ observed that large visible grains have low values of stored energy and concluded that stored energy is the driving force for overcoming the Smith-Zener pinning pressure that is provided by pinning particles such as primary $\gamma^{\prime}$. The selective grain growth

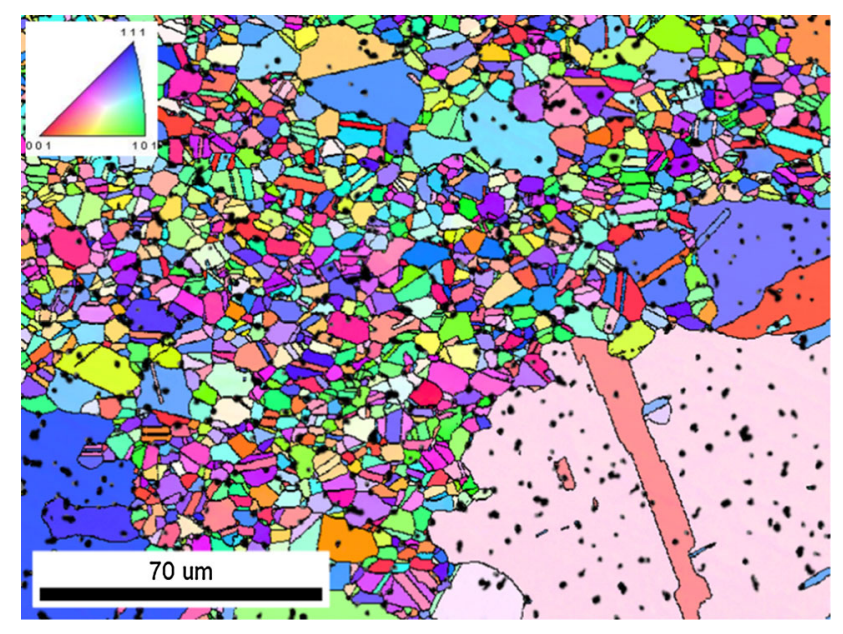

Fig. 2-Inverse pole figure (IPF) from EBSD of RR1000 material that had been forged to 0.4 strain then subjected to a slow heating ramp to the $\gamma^{\prime}$ solvus temperature. Primary $\gamma^{\prime}$ precipitates are shown as black particles; these are $\mathrm{Cr}$ lean areas that were identified from energy dispersive x-ray spectroscopy. Reprinted with permission from Ref. 27. is due to the activation of a few nuclei (from low forging strains) that have sufficient stored energy to exceed a critical value, which appears to decrease with increasing heating time for super-solvus solution heat treatment. This suggests that the observed behavior is a recrystallization phenomenon that requires a critical strain or stored energy. Miller et al. ${ }^{[25]}$ have also shown that the low grain growth front velocities, less than $1 \mu \mathrm{m}$ per $\mathrm{s}$, that have been cited for abnormal grain growth in other alloys, were not found in René 88DT. Much higher values were reported, suggesting that the critical process is not abnormal grain growth but abnormal recrystallization with a low density of nuclei.

A new dynamic recrystallization mechanism (heteroepitaxial recrystallization) has recently been observed in nickel disk alloys. ${ }^{[32]}$ Nuclei for this form of recrystallization are established from a $\gamma^{\prime}$ to $\gamma$ phase transformation at the periphery of or inside primary $\gamma^{\prime}$ particles as a result of slow cooling from temperatures below $T_{\text {solvus. }}$. These can produce recrystallized grains that completely surround the primary $\gamma^{\prime}$ particles. The phenomenon is prevalent at forging temperatures of about $100{ }^{\circ} \mathrm{C}$ below $T_{\text {solvus, }}$ at strain rates of 0.01 per s and in regions of the forging that receive low strain, typically less than 0.6 strain. Under these conditions, the heteroepitaxially recrystallized fraction can be high, between 10 and 20 pct in laboratory samples and higher in large forgings. If higher forging temperatures are used, the $\gamma$ surrounding the primary $\gamma^{\prime}$ particles tends to dissolve. Fewer or no heteroepitaxial recrystallized grains are present when lower forging strain rates (of about 0.001 per second) are used. The activity of this phenomenon coincides with the conditions for large visible grains. However, there are no reports currently in the literature that link heterogeneous recrystallization with the occurrence of large visible grains. It should also be noted that large visible grains are often detected on the surface of forgings from etch inspection. This is inconsistent with heteroepitaxial recrystallization as the surface of forgings will receive the fastest cooling rates after forging.

\section{Effect of Cooling from Solution Heat Treatment on Yield and Tensile Strength}

While composition determines the volume fraction and strengthening potency of $\gamma^{\prime}$, the size, shape, and spatial distribution of these strengthening precipitates are also derived from the rate of cooling following solution heat treatment. Forgings are held at solution heat treatment temperatures and cooled at controlled or predictable rates. For PM alloys or alloys with similar levels of $\gamma^{\prime}$ precipitates, fan, ducted-nozzle air, or compressed air quenching is often used to produce the required strength levels uniformly throughout the forging while minimizing thermal gradients and therefore residual stresses. ${ }^{[33]}$ Cooling rates in forgings depend on the forging shape, the thermal physical material properties of the alloy, and the cooling intensity of the cooling media. An optimized balance between strength and levels of residual stress in forgings can be achieved using quenching facilities that are computer-controlled 
to tailor the cooling process for each forging geometry using bespoke fixtures, process simulation, and optimization software. ${ }^{[33]}$

It is understood that secondary $\gamma^{\prime}$ precipitates nucleate over a limited range of temperatures from $T_{\text {solvus }}$. This critical temperature range, which can be determined using single sensor differential scanning analyses (SSDTA), ${ }^{[34]}$ shows a small variation as a result of differences in cooling rate, producing lower precipitation temperatures from faster cooling rates. ${ }^{[35]}$ The nucleation event dominates precipitation at fast cooling rates, which results in many small secondary $\gamma^{\prime}$ precipitates. ${ }^{[36]}$ The distance between the particles is therefore small. For slower cooling rates, there is a lower nucleation rate and more time for particle growth. Consequently secondary $\gamma^{\prime}$ precipitates are coarser and deviate from a spherical shape as their diffusion and strain fields overlap $^{[37]}$ (Figure 3).

Semiatin et al. ${ }^{[36]}$ have investigated the evolution of $\gamma^{\prime}$ precipitates in the $\gamma$ matrix by varying the cooling rates from the solution heat treatment temperature. Cooling rates were found to have negligible impact on the nucleation of such precipitates during cooling. However, there was a strong dependence of the number density of precipitates on cooling rates. Slower cooling rates result in coarser precipitates and lead to different morphology than the spheroidal particles found as the result of higher cooling rates (as illustrated in Figure 3 for RR1000). Assuming the precipitates are spherical with radius $\mathrm{r}$, the model below was proposed to describe the growth of $\gamma^{\prime}$ precipitates during continuous cooling, ${ }^{[38]}$

$$
\frac{d r}{d t}=2 \lambda^{2} \frac{D}{r}
$$

where $\lambda^{2}$ is related to the finite matrix supersaturation $\Omega$ through

$$
\left(\lambda^{2} \exp \left(\lambda^{2}\right)\right) \cdot\left[\left(\exp \left(-\lambda^{2}\right)\right)-\left(\lambda \pi^{1 / 2}\right) \operatorname{erfc}(\lambda)\right]=\frac{\Omega}{2}
$$

and $D$ is the effective diffusivity of the rate-limiting solutes. Semiatin et al. ${ }^{[39]}$ also suggested that using the geometric average of each solute to calculate the total diffusivity (as in Reference 40) provided the equivalent result to the diffusivity of $\mathrm{Cr}$ in the $\mathrm{Ni}-\mathrm{Cr}$ binary alloy. Thus, simplifying the extent of inputs required to calculate the effective diffusivity rather than total diffusivity.

The affinity for particle coarsening is low for many small $\gamma^{\prime}$ precipitates that have nucleated and retained supersaturation during continuous cooling. ${ }^{[36]}$ This can be critical during the heating and soaking of material at the primary working temperatures for forming standard geometry billets, which are subsequently near net shape forged or receive sub-solvus heat treatments, where the $\gamma^{\prime}$ particles are not completely dissolved in the $\gamma$ matrix.

A model was proposed, as shown below, to describe the coarsening of secondary $\gamma^{\prime}$ precipitates during continuous cooling ${ }^{[36]}$ :

$$
\bar{r}^{3}-\bar{r}_{o}^{3}=\frac{8 w(\phi) D \sigma C_{\gamma}\left(1-C_{\gamma}\right) V_{M}}{9 R T\left(C_{\gamma^{\prime}}-C_{\gamma}\right)^{2}\left[1+\frac{\partial \ln v}{\partial \ln C_{\gamma}}\right]}
$$

where $\bar{r}^{3}-\bar{r}_{o}^{3}$ represent the average instantaneous and initial particle radii, $w(\phi)$ is a factor to correct for the finite volume fraction of particles, $C_{\gamma^{\prime}}$ and $C_{\gamma}$ are the equilibrium concentrations of the rate-limiting solute in the matrix and precipitate, respectively, $D$ is the solute diffusivity in $\gamma, \sigma$ is the $\gamma-\gamma^{\prime}$ surface energy, $V_{\mathrm{M}}$ is the molar volume of the precipitate, $R$ is the gas constant, $\mathrm{T}$ is temperature in Kelvin, and $v$ is the activity coefficient for the rate-limiting solute $(\mathrm{Cr})$ in the $\gamma$ matrix of the specified composition. It is important to note that this model assumes that coarsening is controlled by the diffusion of a single rate-limiting solute. ${ }^{[36]}$ Alloys with near-zero misfit between the $\gamma$ and $\gamma^{\prime}$ phases, such as RR1000, produce dendritic $\gamma^{\prime}$ precipitates from slow cooling rates ${ }^{[41]}$ below about $1^{\circ} \mathrm{C} / \mathrm{s}$ as a result of a preferential crystallographic growth direction, which is understood to be strain induced. ${ }^{[42]}$

For coarse grain microstructures that are produced from super-solvus solution heat treatment, there are also significant differences in composition, size, and shape between secondary $\gamma^{\prime}$ precipitates at grain boundaries and those in intragranular locations. Mitchell et al. ${ }^{[41]}$ found that grain boundary precipitates in RR1000 were larger than intragranular ones and were much less
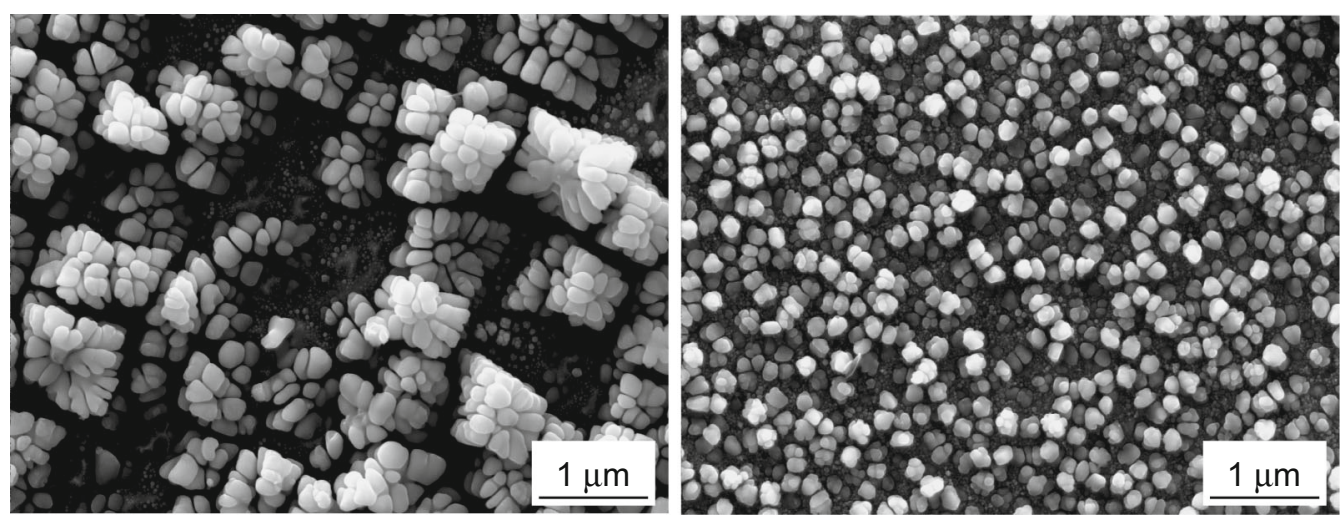

Fig. 3- Secondary electron image of deep etched coarse grain RR1000, which has been cooled from $1170{ }^{\circ} \mathrm{C}$ to $871{ }^{\circ} \mathrm{C}$ at rates of $0.1{ }^{\circ} \mathrm{C} / \mathrm{s}$ (left) and $5{ }^{\circ} \mathrm{C} / \mathrm{s}$ (right). The images show the effect of cooling rate on the size, number density, and morphology of intragranular secondary $\gamma^{\prime}$ precipitates. An electrolytic 10 pct phosphoric acid etch was used. 
spherical. While the number of precipitates that was characterized by transmission electron microscopy (TEM) was small, Mitchell et al. reported that the composition of intergranular precipitates was more consistent than the smaller spherical intragranular precipitates and showed higher concentrations of $\mathrm{Al}$, $\mathrm{Ti}, \mathrm{Ni}, \mathrm{Ta}$, and $\mathrm{Zr}$ ( $\gamma^{\prime}$ forming elements) and reduced levels of $\mathrm{Co}, \mathrm{Cr}$, and Mo ( $\gamma$ forming elements). As grain boundaries provide a preferential path for diffusion of $\gamma^{\prime}$ forming elements, intergranular $\gamma^{\prime}$ precipitates nucleate before the intragranular precipitates during cooling below $T_{\text {solvus, }}$, perhaps as a result of heterogeneous nucleation, and have a longer time for particle coarsening. As indicated above, the shape of the grain boundary precipitates from slow cooling is dependent on the alloy composition and any strain induced preferential directional coarsening. ${ }^{[42]}$ In alloys with near-zero misfit, dendritic or fan-shaped $\gamma^{\prime}$ precipitates that nucleate at grain boundaries push the boundaries locally, producing serrations. ${ }^{[43]}$ This grain boundary morphology is beneficial for improving stress rupture life ${ }^{[44]}$ and resistance to time-dependent crack growth ${ }^{[45]}$ but may have less appealing detriments to yield stress and minimum creep rate due to the necessity for very slow cooling rates over the temperature range for nucleating grain boundary $\gamma^{\prime}$ precipitates.

Generally, a power-law expression can be used to correlate either secondary $\gamma^{\prime}$ size or strength with cooling rate. There are numerous examples in the literature, for example ${ }^{[46-51]}$ that show that increasing cooling rates from solution heat treatment reduce the size of secondary $\gamma^{\prime}$ size, producing higher values of yield stress and tensile strength. This behavior is the result of strong-pair coupling, i.e., when the size of the $\gamma^{\prime}$ precipitates is larger than the spacing between the pairs of dislocations that are cutting the particles. It has been proposed that highest yield strength levels are achieved in compositions with high $\gamma^{\prime}$ volume fractions by developing the size of $\gamma^{\prime}$ precipitates $(15-50 \mathrm{~nm})$ that optimize both weak and strong-pair coupling. ${ }^{[14,52]}$ However, such a unimodal size distribution of $\gamma^{\prime}$ precipitates is likely to have a negative impact on ductility. ${ }^{[52]}$

In practice, the rates of cooling that are applied to advanced PM alloy forgings are limited to rates that optimize time-dependent crack growth behavior and avoid quench cracking ${ }^{[53]}$ from super-solvus solution heat treatment, and the desire to optimize residual stresses in forgings for component manufacture and service life. Quench cracking can occur in alloys that show poor ductility or fracture properties at the solution heat treatment temperature as a result of incipient melting at grain boundaries. This is likely to occur if the alloy has a high $T_{\text {solvus }}$ value, which is within $20{ }^{\circ} \mathrm{C}$ to 30 ${ }^{\circ} \mathrm{C}$ of the incipient melting temperature.

\section{E. Effect of Precipitates on Resistance to Creep Deformation}

There are also examples in the literature that report the effect of cooling rate on creep strain accumulation and stress rupture life. ${ }^{[46,49,51,54,55]}$ It is evident that rapid cooling from solution heat treatment enhances resistance to creep deformation. As indicated earlier, such cooling rates nucleate a high density of small secondary $\gamma^{\prime}$ precipitates that are separated by small $\gamma$ channels. An additional consequence of rapid cooling and the nucleation of many small secondary $\gamma^{\prime}$ precipitates is a reduction in the availability of solute and space for tertiary $\gamma^{\prime}$ precipitates, which reduces the volume fraction of these sub $50 \mathrm{~nm}$ particles. This will be discussed later. However, the effect of cooling rate is relevant to all temperatures that incur creep deformation, although any benefit from rapid cooling diminishes above $800{ }^{\circ} \mathrm{C}$ once secondary $\gamma^{\prime}$ precipitates coarsen.

Detailed TEM by Unocic ${ }^{[55]}$ has identified the creep mechanisms that operate in powder Ni alloy René 104 (or ME3) at temperatures between $677{ }^{\circ} \mathrm{C}$ and $815^{\circ} \mathrm{C}$ and stresses of 345 to $724 \mathrm{MPa}$. This study examined material that had a starting tertiary $\gamma^{\prime}$ precipitate size of $30 \mathrm{~nm}$ on average. Different mechanisms were detected, depending on the temperature and stress condition and the accumulated strain. Initially these involve $a / 2\langle 110\rangle$ dislocations in the $\gamma$ matrix at low strains, which at temperatures below $704^{\circ} \mathrm{C}$ progressed to shearing of the $\gamma$ matrix and $\gamma^{\prime}$ precipitates by a microtwinning mechanism. At a higher temperature of $760^{\circ} \mathrm{C}$ and a stress of $345 \mathrm{MPa}$, the shearing mechanism involved stacking faults. From creep tests at $815^{\circ} \mathrm{C}$ and $345 \mathrm{MPa}$, it was found that dislocations were able to climb over or bypass $\gamma^{\prime}$ precipitates, presumably using thermally activated processes.

At temperatures below about $750{ }^{\circ} \mathrm{C}$, creep strain accumulation is also very sensitive to post-solution (precipitation or aging) heat treatment (P-SHT), which determines the volume fraction and size of tertiary $\gamma^{\prime}$ precipitates. Such heat treatments are designed to relieve residual stresses from quenching, following solution heat treatment and to grow the tertiary $\gamma^{\prime}$ precipitates to a desired size distribution and volume fraction. It has been found for alloys $720 \mathrm{Li}$ and RR1000 that an optimized resistance to creep is achieved by producing a unimodal size distribution of fine tertiary $\gamma^{\prime}$ precipitates with a volume fraction of at least 3 pct and an average size of $15 \mathrm{~nm}$. This typically involves a 4 to 24 hour soak at temperatures between $650{ }^{\circ} \mathrm{C}$ and $800{ }^{\circ} \mathrm{C}$, and will vary from alloy-to-alloy and the need to minimize heat treatment time. However, such a P-SHT is not as effective as shorter duration, higher temperature excursions for relieving residual stresses, which at room temperature can exceed the material yield stress for alloys that contain high levels of $\gamma^{\prime}$ precipitates. While an initial, fine tertiary $\gamma^{\prime}$ size optimizes creep resistance, the particles will coarsen during exposure above $700{ }^{\circ} \mathrm{C}$ and will eventually dissolve, particularly rapidly from excursions above $800{ }^{\circ} \mathrm{C}$. Locq et al. ${ }^{[56]}$ reported that NR3 material that had been exposed to $800{ }^{\circ} \mathrm{C}$ for 500 hours showed high creep strain rates at $700{ }^{\circ} \mathrm{C}$ as no tertiary $\gamma^{\prime}$ precipitates remained, having dissolved. These fine particles that reside in the $\gamma$ channels between the secondary $\gamma^{\prime}$ precipitates provide a resistance to glide of $a / 2\langle 110\rangle$ dislocations in the $\gamma$ phase, which are required to shear the tertiary $\gamma^{\prime}$ particles. 
A 2-stage P-SHT is often preferred for PM alloys, the first stage being a short soak at a temperature above 800 ${ }^{\circ} \mathrm{C}$, such as $843{ }^{\circ} \mathrm{C}\left(1550{ }^{\circ} \mathrm{F}\right)$. This provides an effective stress relief from quenching and grows a proportion of the tertiary $\gamma^{\prime}$ precipitates that could be present, to an average size of 25 to $40 \mathrm{~nm}$. Subsequent coarsening of these particles during long exposures from in-service operation at temperatures at or below $700{ }^{\circ} \mathrm{C}$ will not significantly degrade yield stress and tensile strength. However, long exposures above $750{ }^{\circ} \mathrm{C}$ will coarsen secondary $\gamma^{\prime}$ particles sufficiently to produce appreciable reductions in strength. ${ }^{[57]}$ In some alloys, the first stage of the P-SHT or long-term thermal exposure will also precipitate $\mathrm{M}_{23} \mathrm{C}_{6}$ carbides on grain boundaries, ${ }^{[58,59]}$ which is unlikely to be beneficial as they (i) are a source of dislocations for initiating creep damage, ${ }^{[55]}$ (ii) remove $\mathrm{Cr}$ from the $\gamma$ matrix and therefore locally reduce the resistance of the grain boundary vicinity to environmental damage, ${ }^{[60]}$ and (iii) can provide a nucleation site for precipitation of sigma $(\sigma)$, a detrimental topologically close packed (TCP) phase. The second stage of the P-SHT is the forementioned 4 to 24 hour exposure at temperatures between $650{ }^{\circ} \mathrm{C}$ and $800{ }^{\circ} \mathrm{C}$ that grows the very fine, circa $15 \mathrm{~nm}$, tertiary $\gamma^{\prime}$ precipitates. Consequently, there is a bimodal size distribution for tertiary $\gamma^{\prime}$ precipitates.

As well as the size and volume fraction of $\gamma^{\prime}$ precipitates, grain size can also affect creep behavior, with increases in average grain size improving resistance to creep deformation particularly at temperatures above $750{ }^{\circ} \mathrm{C}$.

\section{F. Time-Dependent Crack Growth}

The design life of disk rotors is determined by low cycle fatigue, i.e., the repeated application of limited plasticity, which leads to the nucleation and growth of fatigue cracks. As materials and components cannot be made without melt or manufacturing anomalies, it is the growth of fatigue cracks that is of primarily importance to safety as loss of integrity of disks cannot be contained within the gas turbine engine and can result in serious damage to, or loss of, the aircraft and fatalities. Due to the sole activity of octahedral $\{111\}$ slip systems at temperatures below $550{ }^{\circ} \mathrm{C}$ to $600{ }^{\circ} \mathrm{C}$, cracks develop from bands of localized strain that extend across grains. ${ }^{[61]}$ As a result, crack growth is transgranular and appears crystallographic, at least for a significant proportion of the crack growth life. At higher temperatures, the rate of oxidation increases and there is slip on both octahedral $\{111\}$ and cubic $\{100\}$ planes. ${ }^{[62]}$

When the peak cyclic load is sustained at these higher temperatures, the crack growth mechanism becomes progressively intergranular as the test temperature and dwell period or cycle time increase. Once temperatures exceed $700{ }^{\circ} \mathrm{C}$, relatively modest dwell periods can produce fully intergranular crack growth with very high rates of crack growth. A significant amount of experimental work has been undertaken to characterize and understand the cause of the grain boundary cracking in Ni-base disk alloys. ${ }^{[63-68]}$ It is agreed that crack growth behavior is also determined by the test environment and the material microstructure. As crack growth remains transgranular under vacuum conditions until test temperatures are high enough to produce creep damage at grain boundaries, ${ }^{[68]}$ oxygen (or water vapor) or oxide species are critical to the damage mechanism. Recent observations of secondary cracks, or primary cracks from interrupted testing, have shown multi-oxide intrusions at some grain boundaries. ${ }^{[69-71]}$ This is also evident at the root of notches that are subject to fatigue loads at oxidizing temperatures. ${ }^{[72]}$ For the oxide intrusions to form ahead of the crack tip during a dwell cycle, cracks must be stationary or grow very slowly for the majority of the time on load and there must be significant enhancement in the rate of oxidation ${ }^{[73]}$ as a result of the very high local stresses adjacent to the crack tip. It is possible therefore that the high rates of crack growth are produced from sudden fracture of the oxide intrusions, which are brittle compared to the unoxidized $\gamma$ and $\gamma^{\prime}$ phases. ${ }^{[73]}$ In coarse grain microstructures, in particular, it has been found that cracks at low stress intensity factors $(K)$ retard, i.e., the growth rate from sustained loading diminishes with increasing $K$ to growth rates associated with transgranular crack growth, or they stop growing. Evans ${ }^{[73]}$ proposed that the volume expansion in forming the oxide intrusion induces a compressive stress in the matrix in the vicinity of the crack tip. This and crack blunting from visco-plastic deformation are likely causes of the observed behavior. Evans provided a schematic illustration of the possible stress profile from the crack tip to the end of the oxide intrusion but conceded that detailed computations were required. Chan $^{[74]}$ and Cimbaro ${ }^{[75]}$ have reported mathematical models for the embrittlement of an elastic-plastic crack by an oxide intrusion. It remains unclear whether dynamic embrittlement, i.e., the reduction of cohesive strength and ductility of grain boundaries due to the presence of oxygen from stress-assisted grain boundary diffusion, ${ }^{[76,77]}$ either prior or after the formation of an oxide intrusion is a contributing factor that produces intergranular crack growth from sustained loading at current service temperatures. Whatever the mechanism, it is apparent that a damage zone develops ahead of the crack tip during the dwell period, which under certain conditions, gives rise to an increment of crack growth from the subsequent unloading and loading parts of the fatigue cycle.

The behavior of cracks to sustained loading in an oxidizing environment has been found to be very sensitive to microstructure: firstly, from differences in grain size, as the phenomenon requires the diffusion of oxygen and displacement of grain boundaries. ${ }^{[78]}$ As there are more grain boundaries in fine grain microstructures, it can be argued that there are more diffusion paths and more grain boundary displacement. Consequently, the rates of crack growth from sustained loading are significantly higher in the fine grain form of an alloy compared to the coarse grain version. Dwell crack growth rates have also been found to vary from differences in cooling rate from solution heat treatment ${ }^{[66-68]}$ and from differences in P-SHT ${ }^{[66-68]}$ or from prolonged exposure at temperatures above $700{ }^{\circ} \mathrm{C}^{[79,80]}$ As discussed earlier, these heat treatment variables 
control the number density, the size of secondary $\gamma^{\prime}$ precipitates, and the $\gamma$ channel spacing between these particles, and the size and volume fraction of tertiary $\gamma^{\prime}$. These aspects of microstructure are important as they determine visco-plastic deformation and therefore the relaxation of stress at the crack tip during sustained loading as the inelastic zone ahead of the crack tip is constrained by surrounding elastic material. It follows then that good resistance to time-dependent crack growth is achieved by a microstructure that promotes stress relaxation and not one that optimizes resistance to plasticity and creep deformation.

The relaxation of stresses in the visco-plastic zone ahead of cracks at these high service temperatures can also explain the observed reduction in crack growth rates during sustained loads, which directly follow small overloads. Telesman et al. ${ }^{[81]}$ have recently shown that $\mathrm{x} 2$ and $\mathrm{x} 5$ reductions in crack growth rate $(d a / d N)$ were produced in LSHR at $704{ }^{\circ} \mathrm{C}$ from overloads of 5 and 10 pct, respectively, prior to 90 -second dwell periods. Growth rates that were similar to those from $0.333 \mathrm{~Hz}$ fatigue cycles were achieved when larger overloads of 15 and 20 pct were applied before the same dwell periods. To simulate the behavior of the visco-plastic zone, stress relaxation tests were conducted by loading to $1.05,1.1$, 1.15 , or 1.2 pct strain and then immediately unloading to 1 pet strain after 1 second. The test bars were held at 1 pet strain for 100 hours. As the unloading of strain occurred in the elastic stress-strain regime, it was found that the overload significantly reduced the initial stress at the start of the stress relaxation testing. Intergranular crack growth was maintained despite the reduction in crack growth rates from the overload cycles.

\section{G. Other Considerations: Phase Stability Versus Environmental Protection}

Alloy design is further complicated by the possible precipitation of detrimental TCP phases during long duration exposures at temperatures above $700{ }^{\circ} \mathrm{C}$. Several approaches can be used to assess whether a composition is likely to precipitate TCP phases. In the past, the phase computation (PHACOMP) ${ }^{[82]}$ method has been used as a guide to avoid the formation of $\sigma$. The approach relies on calculating the average electron vacancy number, $\mathrm{Nv}$, for the alloy and defining an alloy specific number, below which the alloy is deemed to be $\sigma$ safe, i.e., will not precipitate the phase. There are examples, notably Alloy 713, that have shown $\sigma$ when they were not expected to, which have led to adjustments to the methodology. ${ }^{[82]}$ An alternative approach has been developed on the basis of theoretical calculations of electronic structure and considers an average Md number, which is an average energy level of $\mathrm{d}$ orbitals of transition metal additions to nickel. It has correctly predicted the occurrence of detrimental topologically close packed phases such as $\sigma$ in a wide range of commercial alloys. ${ }^{[83]}$ However, the accuracy of the approach relies on defining a critical average $\mathrm{Md}_{\gamma}$ value, below which a $\sigma$ free microstructure is assured. Guedou et $a l .{ }^{[84]}$ proposed that alloys can be designed using a $\operatorname{Md}_{\gamma}$ value of 0.915 . Two compositions were made to this $\mathrm{Md}_{\gamma}$ value, one was free of TCP phases, while the other showed amounts of $\sigma$ phase, which were considered too high for disk applications. In latter work, Reed et al. ${ }^{[3]}$ calculated that alloys for which the $\mathrm{Md}_{\gamma}$ number was less than 0.88 would be free of deleterious $\sigma$ phases.

Phase diagram modeling can be used in several ways to predict whether an alloy will precipitate $\sigma$ during heat treatment or in service. The first is to simply consider the thermodynamic $\sigma$ solvus temperature or the mole pct of $\sigma$. The second is to predict time-temperature-transformation diagrams using available diffusion databases for $\mathrm{Ni}$ alloys and a modified Johnson-Mehl-Avrami model, which requires thermodynamic predictions for the concentration of elements that partition to the $\sigma$ phase as an input. ${ }^{[85]}$

The approaches described above are a starting point for experimental work as ultimately, making the composition and exposing it to long times at likely service operating temperatures is the only method of completely understanding whether the microstructure is free from harmful topologically close packed (TCP) phases. ${ }^{[58,86]}$ A recent study ${ }^{[86]}$ has compared methods for quantifying TCP in Ni-base superalloys. Results from synchrotron $\mathrm{x}$-ray diffraction of solid samples and laboratory x-ray diffraction of extracted residues were in good agreement but the methods were only able to quantify phases that were present at levels greater than about 0.3 wt pct. Smaller quantities can be detected by electron microscopy but not necessarily quantified unless by image analysis.

The necessity to design alloys with high $\gamma^{\prime}$ and Mo, W content, that are free of TCP phases such as $\sigma$ ([Ni, Co, $\mathrm{Fe}]_{\mathrm{x}}[\mathrm{Cr}, \mathrm{Mo}, \mathrm{W}]_{y}$ where $x$ and $y$ vary between 1 and 7) can compromise the resistance to environmental damage as this is determined primarily by the amount of $\mathrm{Cr}$ in the alloy to form chromia scale, notably for temperatures above $650{ }^{\circ} \mathrm{C} \cdot .^{[87,88]}$ This is exacerbated by high levels of $\mathrm{Ti}$ that dope the chromia scale, segregating primarily to grain boundaries and form large rutile nodules above the chromia. ${ }^{[87,89]}$ The end result is that initial rates of the thickening kinetics of the chromia scale are considerably higher than those expected for Ti-free chromia, for example in alloys such as Alloy 718 and ATI 718Plus ${ }^{\mathrm{TM}}$. In many alloys with Co values below about 20 at. pct, the oxidation resistance can be correlated to $\mathrm{Cr} / \mathrm{Ti}$ ratio in at. pct. Unexpectedly good oxidation resistance was reported recently by Christofidou et al. ${ }^{[18]}$ however, for alloys A and B in Table I. While evidence was not presented to explain the behavior, it was attributed to the beneficial contributions of $\mathrm{Ta}$ and Co. Tantalum may form protective spinel oxides or assist in establishing a protective chromia scale. Cobalt may change the partitioning behavior of $\mathrm{Cr}$ to $\gamma$ only.

Eta $(\eta)$ phase, which has the chemical composition of $\mathrm{Ni}_{3} \mathrm{Ti}$ or $\mathrm{Ni}_{3} \mathrm{Al}_{0.5} \mathrm{Nb}_{0.5}$, is another phase that is not necessarily desirable, particularly if it forms during thermo-mechanical processing (Figure 4). It competes with $\gamma^{\prime}$ for $\mathrm{Ti}, \mathrm{Nb}$, Ta, and Al but may only exist over a limited temperature range. A study by Antonov et al. ${ }^{[00]}$ found that $\delta$ and/or $\eta$ formed in preference to $\gamma^{\prime}$ when the $\mathrm{Al} /(\mathrm{Ti}+\mathrm{Nb}+\mathrm{Ta}$ ) ratio was less an 0.85 (in at. pct). 


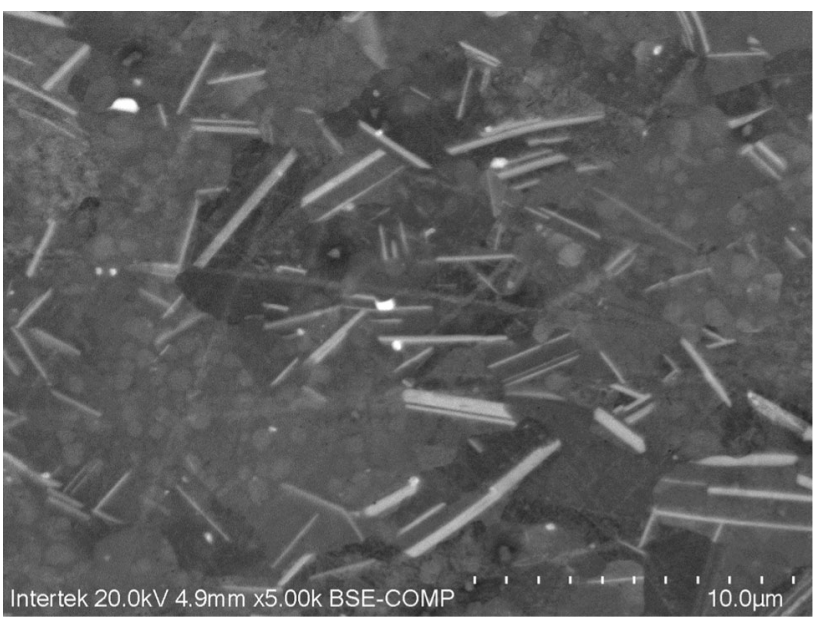

Fig. 4-Backscattered electron image of Alloy B (Table I) following isothermal forging at $1090{ }^{\circ} \mathrm{C}$ of a powder compact (HIP at 1107 $\left.{ }^{\circ} \mathrm{C}\right)$. The white lenticular phase is $\eta$.

A graph from the Antonov et al. paper has been updated in Figure 5 to include those development alloys from this paper, from Guedou et al. ${ }^{[84]}$ and from Bain et al..$^{[91]}$ that have shown or reported $\eta$ phase. Of the alloys from this study, $\eta$ in Alloy B was found after forging at 1090 ${ }^{\circ} \mathrm{C}$ (Figure 4) and in Alloy D after hot isostatic pressing at $1107^{\circ} \mathrm{C}\left(2025^{\circ} \mathrm{F}\right)$. During long exposures in air, $\eta$ can also form near the surface of alloys that have an $\mathrm{Al} /$ $(\mathrm{Ti}+\mathrm{Nb}+\mathrm{Ta})$ ratio just above 0.85 . This is possible due to local changes in composition that occur from the development of external $\mathrm{Ni}, \mathrm{Co}, \mathrm{Ti}$, and $\mathrm{Cr}$ oxide nodules and internal $\mathrm{Al}$ oxide intrusions and $\mathrm{Ta}$ oxide films, the latter of which are present below the chromia scale. Eta can be found below the internal Al oxide intrusions. The presence of the phase on local visco-plastic behavior and strain to failure is currently unclear.

\section{H. Concluding Remarks}

The preceding sections have discussed approaches that are necessary to improve the temperature capability of Ni alloys for high-pressure disk rotor applications in aircraft engines. For the temperatures and high climb rates that are imposed on these components in modern aircraft engines, the resistance to time-dependent or dwell crack growth often limits the temperature capability of alloys and the design life of components. While damage tolerance is a priority, other properties such as strength, phase stability, and resistance to environmental damage are also critical for design. Achieving the desired balance of properties requires that complex superalloy compositions be produced using powder metallurgy and low strain rate, isothermal forging. These material manufacturing methods are critical in producing large forgings that show a narrow range of grain size after super-solvus solution heat treatment. As such, alloys need to be designed to produce the required

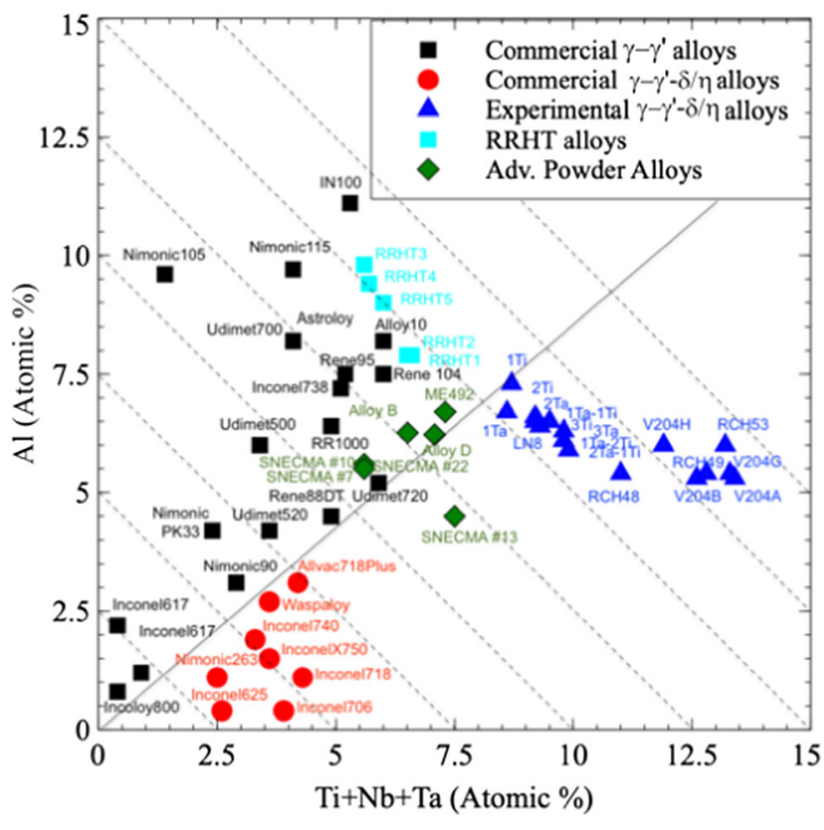

Fig. 5- Graph adapted from Antonov et al. ${ }^{[90]}$ indicating that alloys that lie below the solid line are likely to precipitate $\eta$ and or $\delta$ phase. The solid line is defined by $\mathrm{Al} /(\mathrm{Ti}+\mathrm{Nb}+\mathrm{Ta})$ ratio of 0.85 . Advanced powder alloys from Table I and Refs. ${ }^{[84]}$ and ${ }^{[91]}$ have been found to precipitate $\eta$.

levels of yield strength from a coarse grain microstructure. This is possible using models that predict precipitation strengthening, i.e., the effects of $\gamma^{\prime}$ composition, volume fraction and size, and the effects of grain size and $\gamma$ matrix strength. The process of quenching forgings from solution heat treatment is also extremely important in optimizing time-dependent crack growth behavior, in avoiding quench cracking, and in controlling residual stresses in forgings for minimizing distortion during component machining and for optimizing service life. In addition, a suitable post-solution heat treatment is necessary for producing the desired dwell crack growth behavior and for relieving residual stresses after quenching. Another critical alloy attribute is phase stability to ensure that detrimental topologically close packed phases such as $\sigma$ do not precipitate at grain boundaries during long exposures at high temperatures. While predictive methods are available, these should be considered as a starting point for experimental verification. As $\mathrm{Cr}$ in the $\gamma$ phase is a contributor to $\sigma$ precipitation, designing a composition with lower levels of $\mathrm{Cr}$ can result in reduced environmental protection, given that chromia is the protective scale that forms at temperatures above $650{ }^{\circ} \mathrm{C}$. However, adequate resistance to oxidation and type II hot corrosion can be realized if the $\mathrm{Ti}$ content in the alloy is reduced sufficiently by replacing it with other $\gamma^{\prime}$ forming elements such as $\mathrm{Ta}$ and $\mathrm{Nb}$. It is recognized that this review has not discussed other important topics such as the effect of $\mathrm{B}, \mathrm{Zr}$, and $\mathrm{C}$ on grain boundary microstructure and properties. 


\section{DESIGN FOR MANUFACTURABILITY OF ADVANCED CAST AND WROUGHT SUPERALLOYS}

\section{A. Legacy Cast and Wrought Superalloys}

Alloy 718 is widely used for disk rotor applications in the compressor and turbine of aircraft engines. The success of the alloy lies in the ease and cost of material manufacture, a low rate of melt anomalies from primary and remelting practices ${ }^{[92]}$ and the appealing material properties that result from forging and either conventional heat treatment or from direct age. ${ }^{[93]}$ This is possible as the alloy composition provides a relatively low volume fraction (about 22 pct) of both gamma double prime $\left(\gamma^{\prime \prime}\right)$ and $\gamma^{\prime}$ strengthening precipitates and thermomechanical processing produces a fine grain (ASTM 10-13) and small $(<50 \mathrm{~nm}) \gamma^{\prime \prime}$ and $\gamma^{\prime}$ precipitates. However, the temperature capability of the alloy is limited to about $600{ }^{\circ} \mathrm{C}$ to $630{ }^{\circ} \mathrm{C}$ as $\gamma^{\prime \prime}$ and $\gamma^{\prime}$ precipitates coarsen during prolonged exposure at temperatures above $600{ }^{\circ} \mathrm{C}$, and at higher temperatures ( $>$ $700{ }^{\circ} \mathrm{C}$ ) meta stable $\gamma^{\prime \prime}$ precipitates transform to $\delta$ phase, further reducing strength. Consequently, there is an opportunity for advanced cast and wrought alloys to occupy a design space in temperature capability between 718 and powder alloys.

Waspaloy and Alloy $720 \mathrm{Li}$ are potential candidates, although Wasploy, with about 26 pet $\gamma^{\prime}$ shows lower yield strength values than 718 , particularly when produced with a coarse grain microstructure. There are also greater challenges in material and component manufacture, whether in terms of melt anomalies, recrystallization, forge cracking, weldability, or twin cracking during machining. However, Alloy 720 and $720 \mathrm{Li}$ with about 44 pct $\gamma^{\prime}$ have been used successfully since the mid-1990s, ${ }^{[94,95]}$ due to competitive strength levels from a fine grain microstructure and a temperature capability of $650{ }^{\circ} \mathrm{C}$ to $700{ }^{\circ} \mathrm{C}$. The low interstitial (Li) version shows improved phase stability compared to the original 720 composition and a reduced propensity to TiN, TiCN inclusions. ${ }^{[95,96]}$. The alloy does require additional controls for successful primary and remelting to minimize inclusion content and multi-step ingot conversion practice to produce a near fully recrystallized billet microstructure. It can be forged successfully using either conventional closed die forging, ring rolling, or low strain rate isothermal forging, which produces near to net envelopes that can significantly minimize input weight.

\section{B. The Need to Consider Manufacturability in Alloy Design}

When designing an alloy for optimum performance in service, it is equally important to consider the manufacturability of the alloy. The ability to manufacture an alloy at scale using a commercially attractive processing route often determines the viability of an alloy, the degree to which the alloy finds insertion in application, and the longevity of the use of the alloy in design. For advanced cast-and-wrought alloys, the characteristics that contribute to improvements in performance in service typically render alloys more difficult to manufacture, i.e., higher refractory element content, higher $\gamma^{\prime}$ content, and stability and size control of multiple precipitate phases. That contradiction between performance and manufacturability makes a system approach to alloy design important and makes it critical to have multiple levels of the development and insertion supply chain engaged from the start of an alloy development effort. Recent alloy developments for turbine engine disks and structural components have found success because of development occurring, in part, across the supply chain.

Olson has advanced the systems approach of computational alloy design ${ }^{[97]}$ and with his colleagues has demonstrated success in using the approach to design and produce high-performance materials including steels and titanium alloys. That system design approach considers the intimate link between manufacturing process steps and the resulting microstructure, mechanical properties, and performance in service.$^{[98]} \mathrm{A}$ system design considers manufacturability, such as the degree of segregation expected during vacuum arc remelting and the effectiveness of homogenizing such a segregated microstructure, but the significance of manufacturability at commercial scale has tended to be minimized, perhaps due to lack of involvement of a metals manufacturer early in the design process. Continuing advancement in computational tools described by Olson and use of pilot scale manufacturing resources ${ }^{[99]}$ provide an alloy development team significant capability to design for manufacturability from the start of alloy development.

The manufacturing of advanced cast-and-wrought superalloys involves many steps, each with challenges affected by alloy design considerations. In primary melt, the tolerance for or intentional addition of trace elements can influence the choice of raw materials and vacuum induction melting (VIM) parameters such as the processing time necessary to refine, the amount of in-process sampling, and when and how to make add-back additions, and the impact can vary with the scale of the melting furnace. A VIM casting process casts electrodes quickly and repeatedly with less consideration of the as-cast electrode structure. However, the solidification behavior of an alloy and the degree of segregation can affect the integrity and ductility of the cast electrode and subsequently impact downstream remelt processes. The melt rate and the ingot size achievable during vacuum arc remelting (VAR) without producing melt segregation defects are strongly affected by alloy composition. Again, the direction of alloy design to improve performance of advanced cast-andwrought alloys by including more refractory solid solution strengtheners, higher $\mathrm{Nb}$ contents, and more boride formers move alloy compositions in the direction of lower manufacturability at scale, especially with respect to electroslag remelting (ESR) and VAR. Ingot diameters are often limited due to the need to maintain a pool shape that avoids formation of melt defects or to limit interdendritic segregation to a degree that can be homogenized by downstream heat treatment. Converting ingots to billet via hot working on an open die press 
is similarly affected by alloy composition. Alloys designed for manufacturability take into consideration heating and cooling rates achievable in ingots greater than $500 \mathrm{~mm}$ in diameter, furnace tolerances, and on-die and transfer times by providing sufficient temperature windows of phase stability and precipitation rates.

\section{Examples}

All factors that should be considered in alloy design that can affect manufacturability are not addressed here, but rather two recently developed advanced cast-andwrought alloys are used as examples that have found application, in part, because manufacturability factors were considered during alloy design: ATI 718Plus ${ }^{\circledR}$ alloy and René 65 alloy (Table II). Both aerospace alloys faced significant manufacturability challenges while targeting improvements in performance in service. The design process for both alloys utilized computational tools and pilot scale process simulations to arrive at alloy compositions with both improved performance and good manufacturability, and both alloys had involvement of the manufacturing supply chain during the alloy design stages. ${ }^{[100,101]}$ Imano et al. ${ }^{[102]}$ also provide a detailed account of applying the system design approach to successful alloy design for manufacturability of an advanced cast-and-wrought Ni-base superalloy for use as an $800{ }^{\circ} \mathrm{C}$-class steam turbine material.

\section{ATI 718Plus Alloy}

ATI 718Plus alloy provides $50{ }^{\circ} \mathrm{C}$ increase in temperature capability compared to alloy 718 and improved manufacturability compared to Waspaloy. ${ }^{[103,104]}$ The alloy design to achieve that performance moved toward a composition taking advantage of improved thermal stability of the $\gamma^{\prime}$ precipitation phase over the $\gamma^{\prime \prime}$ phase that is used for strengthening alloy 718 . With the change to increased $\gamma^{\prime}$ phase fraction in the alloy (about $30 \mathrm{pct}$ ) came the need to balance the performance benefit in service with the decrease in hot workability and weldability associated with $\gamma^{\prime}$ containing cast-and-wrought alloys such as Waspaloy or René 41. ${ }^{[104]}$

The hot workability of cast-and-wrought Ni-base superalloys during conversion from ingot to billet decreases with increasing $\gamma^{\prime}$ phase fraction. ${ }^{[105]}$ Higher $\gamma^{\prime}$ fraction comes with faster precipitation of the $\gamma^{\prime}$ phase upon surface cooling below the solvus during hot working. The thermal gradients that develop during ingot-to-billet conversion of commercially relevant ingot diameters (Figure 6) coupled with precipitation of the strengthening phase upon cooling in the workpiece creates a corresponding gradient in flow stress and ductility that must be managed during conversion. When radiative and convective cooling occur during transfer from the furnace to the forging dies and during the forging process, and from surface chilling due to die contact, alloys primarily strengthened with the $\gamma^{\prime}$ phase are subject to severe surface cracking because the surface cooling rates are not fast enough to bypass the short time nose in the TTT curve of the $\gamma^{\prime}$ phase. As such, $\gamma^{\prime}$ phase precipitation can occur and is accompanied by changes in mechanical properties that lead to surface cracking.

A computational thermodynamic approach was taken during the alloy composition design of ATI 718Plus in order to understand the balance between the advantage of higher $\gamma^{\prime}$ content on thermal stability and the negative impact of that microstructure change on manufacturability. Alloy 718 has favorable hot workability due to the relatively slow precipitation kinetics of the $\gamma^{\prime \prime}$ phase ${ }^{[106]}$ and relatively low fraction of the $\gamma^{\prime}$ phase, allowing billet conversion to be performed without significant $\gamma^{\prime \prime}$ precipitation in the cooling regions near the surface of the billet.

The design philosophy for ATI 718Plus alloy was to adjust the $\mathrm{Al}$ and $\mathrm{Ti}$ concentrations in the alloy to achieve a primarily stable $\gamma^{\prime}$ strengthened alloy with improved high-temperature performance while maintaining manufacturability by balancing $\gamma^{\prime}$ content and precipitation behavior. ${ }^{[107]}$ Further, $\gamma^{\prime} / \gamma$ matrix mismatch had to be controlled to limit coarsening behavior of the $\gamma^{\prime}$ phase. The use of computational thermody-

*JMatPro ${ }^{\circledR}$ is a registered trademark of Sente Software Ltd., UK.

namics software (JMatPro* was utilized to explore the compositional design space; the $\mathrm{Al} / \mathrm{Ti}$ ratio and total $\mathrm{Al}$ + Ti alloy content were identified to achieve a primarily $\gamma^{\prime}$ phase strengthened alloy ${ }^{[107]}$. Increasing $\mathrm{Al} / \mathrm{Ti}$ ratio and $\mathrm{Al}+\mathrm{Ti}$ content increased the amount of $\gamma^{\prime}$ in the alloy. The time to precipitate $\gamma^{\prime}$ as predicted by the time-temperature-transformation (TTT) curves was similarly investigated over the alloy composition space (Figure 7). The nose of the $\gamma^{\prime}$ TTT curve sits considerably to the left toward shorter times to precipitate the $\gamma^{\prime}$ phase compared to the time to precipitate the $\gamma^{\prime \prime}$ phase in alloy 718 signifying decreasing hot workability compared to alloy 718 . These curves combined with experimental testing of thermal stability and resistance to stress-rupture failure after thermal exposure provided the alloy designer the information necessary to balance performance and hot workability. $\mathrm{An} \mathrm{Al} / \mathrm{Ti}$ atomic ratio of 3.4 and $\mathrm{Al}+\mathrm{Ti}$ content of about 4 were ultimately

Table II. Nominal Composition of ATI 718Plus Alloy and René 65 Alloy (Wt Pct)

\begin{tabular}{lccccrrrrrrr}
\hline Alloy & Ni & Cr & Mo & W & Co & Fe & Nb & Ti & Al & Zr & B \\
\hline ATI 718Plus & Bal. & 18 & 2.8 & 1 & 9 & 10 & 5.4 & 0.7 & 1.45 & - \\
René 65 & Bal. & 16 & 4 & 4 & 13 & 1 & 0.7 & 3.7 & 2.1 & 0.05 & 0.016 \\
\hline
\end{tabular}




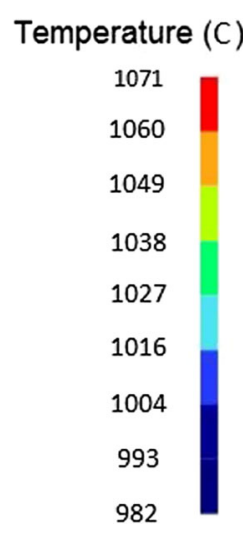

Fig. 6-Cross-sectional thermal profile calculated using DEFORM software during an open die conversion pass for a superalloy ingot being converted from ingot to billet. The billet diameter is $400 \mathrm{~mm}$.

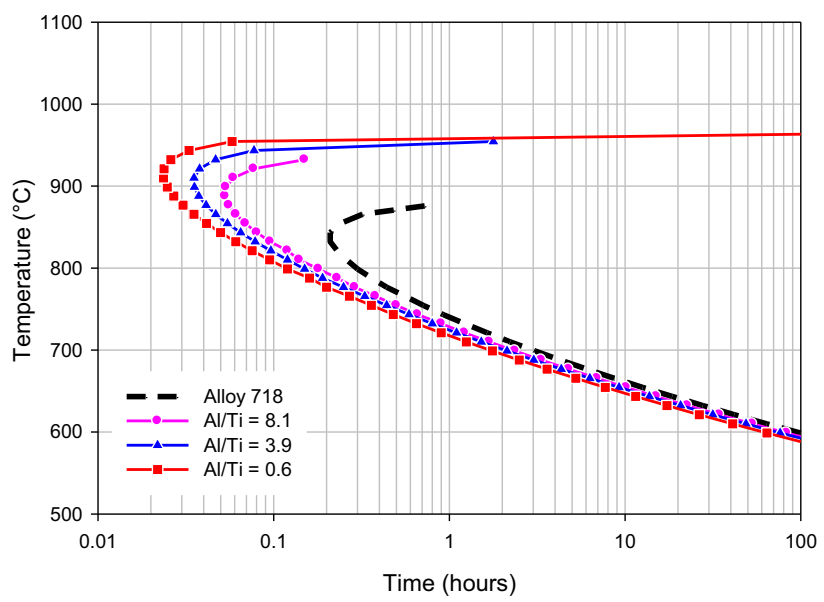

Fig. 7-Calculated isothermal Time-Temperature-Transformation diagram showing the calculated effect of $\mathrm{Al} / \mathrm{Ti}$ ratio (at. pct) on the precipitation behavior of the $\gamma^{\prime}$ phase in ATI 718Plus alloy compared to the precipitation of $\gamma^{\prime \prime}$ in alloy 718. Reprinted with permission from Ref. 107.

identified as the best compromise for improved performance and acceptable hot workability. ${ }^{[107]}$

The $T_{\text {solvus }}$ of the precipitating phases in an alloy (carbides, borides, intermetallic phases) is important to consider with respect to manufacturability of advanced cast-and-wrought superalloys. These second phases can be used for controlling grain size during hot working (for example References 108 and 109) resulting in fine grain billet microstructures. Fine grain processing in alloy 718 is performed at temperatures below the $\delta$ $T_{\text {solvus }}\left(\sim 1027{ }^{\circ} \mathrm{C}\right)$ and above the $\gamma^{\prime \prime} T_{\text {solvus }}(\sim 886$ $\left.{ }^{\circ} \mathrm{C}\right) .{ }^{108]}$ That temperature window is an important measure of hot workability; the $150{ }^{\circ} \mathrm{C}$ hot working range is considerably greater than the typical furnace operating range and the extent of workpiece cooling (Figure 6) that is encountered in billet production.

Similar to balancing the performance benefit of higher $\gamma^{\prime}$ content with the precipitation rate of $\gamma^{\prime}$, the composition design of ATI 718Plus alloy considered the temperature range between the $\gamma^{\prime} T_{\text {solvus }}$ and the $\delta$ $T_{\text {solvus }}$ in order to insure microstructure control during hot working and heat treatment. Thermodynamic calculation software (JMatPro) coupled with thermal

**DEFORM ${ }^{\circledR}$ is a registered trademark of Scientific Forming Technologies Corporation, 2545 Farmers Drive, Suite 200, Columbus, Ohio 43235

mechanical processing simulations (DEFORM**) was used to predict the relative $T_{\text {solvus }}$ of the $\gamma^{\prime}$ and $\delta$ phases and the thermal profile in the work piece during hot working prior to finalizing the alloy composition in order to insure sufficient window for hot working and heat treatment. The $\delta$ phase $T_{\text {solvus }}$ in ATI 718Plus is in the range from $1002{ }^{\circ} \mathrm{C}$ to $1013{ }^{\circ} \mathrm{C}$ and the $\gamma^{\prime} T_{\text {solvus }}$ is in the range from $977{ }^{\circ} \mathrm{C}$ to $982{ }^{\circ} \mathrm{C}$. The $30{ }^{\circ} \mathrm{C}$ hot workability range is near the minimum temperature window suitable for manufacturing without significant cracking and challenges for microstructure control, and was deemed an acceptable balance between hot working window and $\gamma^{\prime}$ phase content. Forging below the $\delta$ phase $T_{\text {solvus }}$ in order to produce fine grain structure requires tight control of the hot working process and equipment.

An adequate manufacturing window for hot working and heat treatment must consider real factors in a commercial production shop such as manufacturing furnace tolerances and variation, transfer times from furnace to dies, manipulation of the work piece entering the press, and cooling when in contact with the forging dies. Modern manufacturing facilities employ advanced equipment controls and statistical process control to limit variation from piece-to-piece. Still, for example, variations in fixed physical distances from furnace to press can lead to a predictable variation in transfer time and consequently the degree of cooling as the piece moves to the press. Alloy design must consider these factors when finalizing a composition.

\section{E. René 65}

René 65 alloy is a cast-and-wrought derivative of the powder metallurgy alloy René 88DT that fills the gap between cast-and-wrought alloys and powder metallurgy alloys for critical rotating parts, and was designed to be manufacturable into parts via hot die forging and ring rolling. ${ }^{[110,111]}$ It has a $\gamma^{\prime}$ content of about 38 pct.

When developing a cast-and-wrought version of an alloy developed originally for powder metallurgy production, several aspects of the cast-and-wrought manufacturing process must be considered in the alloy design, including: solidification segregation, microstructure development during billet conversion, and hot workability. Powder metallurgy compositions are typically highly alloyed and a powder metallurgy production route has been employed because the composition may not be considered castable using the cast-and-wrought route. In the case of René 65 alloy, the René 88DT composition was proven to deliver desirable performance in service. ${ }^{[12]}$ The alloy design for René 65 centered on manufacturability as a cast-and-wrought alloy while maintaining the desired performance in service. $^{[110]}$ 
The composition design of René 88DT took advantage of the high solidification rates achieved during gas atomization compared to ingot solidification during VAR. That composition is not robust against solidification segregation, suppression of the liquidus temperature, or deleterious inclusions. When adapting that powder composition for cast-and-wrought processing, the composition of René 65 had to be adjusted to reduce the probability of solidification defects such as deleterious nitride stringers common in cast-and-wrought alloys. ${ }^{[110]}$

The formation of carbonitride stringers are common in cast-and-wrought superalloys and can negatively affect the fatigue performance. ${ }^{[113,114]}$ The formation of some such stringers is unavoidable in a commercially viable manufacturing process, but the severity of the stringers can be controlled by tight controls on interstitial content. In the design of alloy René 65 , the effect of interstitial content on the occurrence of stringers was studied and a low interstitial content composition was specified. $^{[110]}$

Another consideration in the alloy design important for cast-and-wrought alloys is the ability to recycle machine turnings and solids in the composition. Many powder metallurgy alloys have narrow composition ranges or contain highly reactive elements that reduce the ability to use processed scrap and may limit the charge make-up to prime raw materials. Thermodynamic software calculations were used to study the effect of minor Fe additions on the phase stability in René 65. A maximum $\mathrm{Fe}$ content of $1.3 \mathrm{wt}$ pct was identified as the limit that the alloy could accommodate and avoid the formation of deleterious $\sigma$ phase. ${ }^{[110]}$

\section{F. Control Technology and Computational Tools}

Recent advances in process simulation modeling and in process control technology have been enabling for design for manufacturing. Commercial thermodynamic calculation software tools such as Thermocalc ${ }^{\dagger}$,

\footnotetext{
${ }^{\dagger}$ Thermo-Calc is the product of Thermo-Calc Software AB, Råsundavägen 18, SE-169 67 Solna, SWEDEN
}

Pandat ${ }^{\ddagger}$, and JMatPro, continue to be improved to be

\footnotetext{
${ }^{\ddagger}$ Pandat ${ }^{\mathrm{TM}}$ is a registered trademark of CompuTherm LLC, 8401 Greenway Blvd Suite 248, Middleton, WI 53562, USA
}

capable of calculating phase equilibria, materials properties, and precipitation and coarsening behavior over a wider range of composition space [for example Refs. 33,115-117]. Commercial and proprietary finite element codes for heat transfer and deformation processing are routinely used in process engineering. Vacuum arc remelting ${ }^{[118]}$ and electroslag remelting ${ }^{[199]}$ process simulations are capable of providing accurate descriptions of the effect of melt process parameters on pool depth and pool shape. Remelt control technology has demonstrated capability to control pool depth and to predict local solidification rate and resulting secondary dendrite arm spacing $^{[120]}$. Such information is vital to developing manufacturing friendly processes for advanced cast-and-wrought alloys containing high quantities of segregation prone elements.

Combining these tools allow the alloy designer to qualitatively observe how the microstructure evolves from a casting to hot-worked billet for a set of processing conditions. While the ability of these tools has not advanced to the point where accurate, site specific prediction of cracking or non-uniform microstructure can be predicted, the use of these computational tools can increase the speed by which alloy design modifications can be tested and reduce the number of full-scale production trials required to achieve an acceptable alloy design or manufacturing process.

\section{G. Concluding Remarks}

Early and intentional consideration of manufacturability has significantly contributed to the successful insertion of recent advanced cast-and-wrought Ni-base superalloys. Alloy designers have involved the supply chain early in the design cycle in order to address manufacturing challenges in concert with optimizing alloy performance in service. This collaboration has led to appropriate trades in alloy design and has reduced the design cycle time and cost. Continued early consideration of manufacturability and the ability to simulate manufacturing processes (computationally and in the pilot plant) can further extend the possibility of developing commercially viable Ni-base wrought alloys with yet better performance in service.

\section{NICKEL SUPERALLOYS FOR FOSSIL ENERGY APPLICATIONS}

Growing global population has challenged the energy industry to provide reliable and efficient sources of energy. Combined with emission and environmental requirements, the development and use of renewable energy sources has increased and will continue to do so in the future. ${ }^{[121]}$ Nevertheless, fossil-based fuels remain the largest source for electricity generation worldwide in 2018 with 38 pct originating from coal. ${ }^{[122]}$ Countries including the United States, China, and India have large coal reserves representing low-cost energy generation. Furthermore, natural gas reserves in the United States have motivated a shift from base-load steam turbine generation to power on demand gas turbines.

In the past 20 years, Advanced-Ultra Supercritical (AUSC) power plant technology has been under development to provide a viable replacement for super and ultra-supercritical coal-fired power plants ${ }^{[123,124]}$ AUSC technology can also be utilized to retrofit existing power plants. By dramatically increasing the steam outlet temperature and pressure, harmful gas emissions can be reduced, while the efficiency of the plant as a whole can increase from approximately 35 pct to near 50 pct. ${ }^{[125]}$ Increasing overall plant efficiency has the added 
benefit of allowing the utility to include advanced carbon capture and sequestration technologies where storage is readily available while not adversely impacting prior plant electrical output to the grid. While the current fleet of coal-fired power plants operate with a maximum steam temperature at the turbine inlet (i.e., high and intermediate pressure turbine) approaching $620{ }^{\circ} \mathrm{C}$, for the most advanced plants, steam temperature is usually much less for the remaining fleet. The advent of AUSC technology worldwide targeted steam temperature between $700{ }^{\circ} \mathrm{C}$ and $750{ }^{\circ} \mathrm{C}$ with National Energy Technology Laboratory (NETL)/Department of Energy (DOE) funding research to develop AUSC technology in the United States to $760{ }^{\circ} \mathrm{C}$ (with research continuing to push the temperature beyond $800^{\circ} \mathrm{C}$ ). As a result, advanced high-strength steels and austenitic stainless steels used in traditional coal-fired power plants cannot be used in the hottest sections of AUSC boilers and turbines.

As the various AUSC programs have arisen in the United States, Europe, Japan, China, and India, exploration in the use of Ni-based superalloy (hereafter superalloy) has significantly expanded because alloys in this class have an exceptional combination of high-temperature 0.2 pct yield stress (YS) and ultimate tensile strength (UTS) and long creep life and superior oxidation capabilities around the targeted operating temperatures. These various programs explore the use of existing superalloys (or existing alloys that have been modified) to AUSC technologies, including boiler pipes and tubes that require welding and specialized fabrication techniques or as large components in the steam turbine (i.e., rotor, rotor casing, valve, valve casing) and boiler (e.g., main steam header), where manufactured sizes can be $\geq 5000 \mathrm{~kg}$.

\section{A. Background Potential for Nickel Superalloys in Energy Applications}

A number of wrought $\gamma^{\prime}$ strengthened superalloys are available commercially as flat or round products, typically in the form of cold rolled sheet or bar and/or hot-rolled plate or round bar. Most of these superalloys, which include R-41, Waspaloy, 263, and X-750, have been around for a long time, dating back to between the 1930s and 1960s. Despite their age, these superalloys are still produced in considerable volume. However, there are serious limitations, which restrict their use in terms of both temperature capability and component fabricability. In short, superalloys with greater strength, such as the R-41 and Waspaloy, are well known to have fabricability, machinability, and weldability problems, especially with regard to thick section welding. ${ }^{[126,127]}$ Conversely, superalloys with better fabricability, such as the 263 and X-750, have much lower temperature capability due to their lower strength.

In the past, designers have worked around these limitations by restricting either the use temperature or the size/geometry of their components. However, the need for an alloy, or alloys, that combine high-temperature strength with excellent fabricability has long been recognized. To meet this need, alloy development programs were initiated at Special Metals Corporation $(740 / 740 \mathrm{H})$ and Haynes International $\left(282^{[128]}\right)$ in the late 1990s. The program objective of the 282 effort, for example, was to achieve creep strength approaching that of Waspaloy and R-41 at temperatures around $870{ }^{\circ} \mathrm{C}$, while having improved fabricability and weldability. Specifically, this alloy was to have significantly better resistance to post-weld strain-age cracking. ${ }^{[127]}$ The end result of this superalloy development program was HAYNES 282 (282 hereafter). The composition of 282 is shown in Table III along with those of several other $\gamma^{\prime}$ strengthened superalloys.

Gamma prime strengthened superalloys represent a significant portion of material selected for use in the high-temperature regions of modern energy systems. These superalloys can be loosely grouped according to their $\gamma^{\prime}$ volume fraction: (1) high $\gamma^{\prime}$ volume fraction superalloys (i.e., $>50$ vol. pct) such as those used in the gas turbine (GT) compressor, or as GT turbine blades/vanes, (2) intermediate $\gamma^{\prime} / \gamma^{\prime \prime}$ volume fraction superalloys (i.e., between 25 and 50 vol. pct) such as those used in GT rotating disks/spacers, and (3) lower $\gamma^{\prime}$ volume fraction superalloys (i.e., $<25$ vol. pct) used in a wide variety of structural components suitable for use in AUSC power plants. ${ }^{[129]}$

The advantage of superalloys with lower $\gamma^{\prime}$ volume fraction is fabricability and to some extent weldability. These superalloys, which include 263, 282, and 740/ $740 \mathrm{H}$, can be fabricated using conventional processing routes, i.e., forging, hot and cold rolling, drawing, to produce sheet, plate, wire, bar, and billet forms. This allows for production of both small and large components at a cost significantly below that of investment cast or isothermally forged products. Furthermore, these superalloys generally can be welded to allow for even greater flexibility in component design. Typical components include rings, seals, transitions, combustors, nozzles, casings, bolts, and many others.

Of the alloys mentioned previously, wrought $\gamma^{\prime}$ strengthened superalloy 282 has been shown to be the most flexible in this regard. ${ }^{[130]}$ This superalloy was initially developed to address two key difficulties with the previously existing superalloys in its family, i.e., greater strength ones. Superalloy R-41 and Waspaloy are well known to have fabricability problems, especially with regard to welding thick sections. Conversely, superalloys with better fabricability, such as 263, are easily weldable but have much lower creep strength at AUSC operating temperatures. Superalloy 282 was developed to possess both excellent fabricability/weldability and good high-temperature strength. Specifically, 282 was designed with creep strength approaching that of Waspaloy and R-41 for temperatures up to $870^{\circ} \mathrm{C}$. A traditional two-step aging process was used for the 282 alloy to nucleate and then grow the $\gamma^{\prime}$ precipitates. However, subsequent work in the AUSC program ${ }^{[129]}$ showed that in thick sections typical for components in power plants $\gamma^{\prime}$ precipitates formed at the nano-scale even in the solution heat-treated condition. Research had shown that creep life in the solution heat-treated condition was not affected (as shown in Figure 8) but the YS of the alloy was lower (as expected from the 
Table III. Typical Average Chemistry of Main Constituent Elements for AUSC Superalloys (Wt Pct)

\begin{tabular}{lllllllllllll}
\hline Alloy & $\mathrm{C}$ & $\mathrm{Ni}$ & $\mathrm{Cr}$ & $\mathrm{Mo}$ & $\mathrm{Co}$ & $\mathrm{Al}$ & $\mathrm{Ti}$ & $\mathrm{Nb}$ & $\mathrm{Mn}$ & $\mathrm{Fe}$ & $\mathrm{Si}$ & $\mathrm{B}$ \\
\hline 105 & 0.12 & 56 & 15 & 0 & 20 & 4.7 & 1.2 & 0 & 1 & 1 & 1 \\
230 & 0.10 & 53 & 22 & 2 & 5 & 0.3 & 0 & 0 & 0.5 & 3 & 0.4 & 0.015 \\
263 & 0.06 & 49 & 20 & 6 & 20 & 0.6 & 2.4 & 0 & 0.6 & 0.7 & 0.4 & 0 \\
282 & 0.06 & 56 & 19.5 & 8.5 & 10 & 1.5 & 2.1 & 0 & 0.3 & 1.5 & 0.15 & 0.005 \\
617 & 0.07 & 54 & 22 & 9 & 12.5 & 1.2 & 0.3 & 0 & 0 & 1 & 0 & 0 \\
CCA617 & 0.06 & 57 & 21.5 & 8.6 & 11.3 & 1.2 & 0.4 & 0.02 & 0.03 & 0.07 & 0.1 & 0.003 \\
625 & 0.03 & 59 & 21 & 9 & 1 & 0.4 & 0.4 & 3.65 & 0.5 & 5 & 0.15 & 0 \\
740 & 0.03 & 48 & 25 & 0.5 & 20 & 0.9 & 1.8 & 2 & 0.3 & 0.7 & 0.5 & 0 \\
740H & 0.03 & 51 & 24.5 & 0.1 & 20 & 1.35 & 1.35 & 1.5 & & 0.1 & 2 & 0.15 \\
Waspaloy & 0.08 & 56 & 19 & 4.3 & 13.5 & 1.5 & 3 & & 0.1 & 0.006 \\
R-41 & 0.09 & 50 & 19 & 9.75 & 11 & 1.5 & 3.15 & & 0.1 & 5 & 0.1 & 0.007 \\
\hline
\end{tabular}

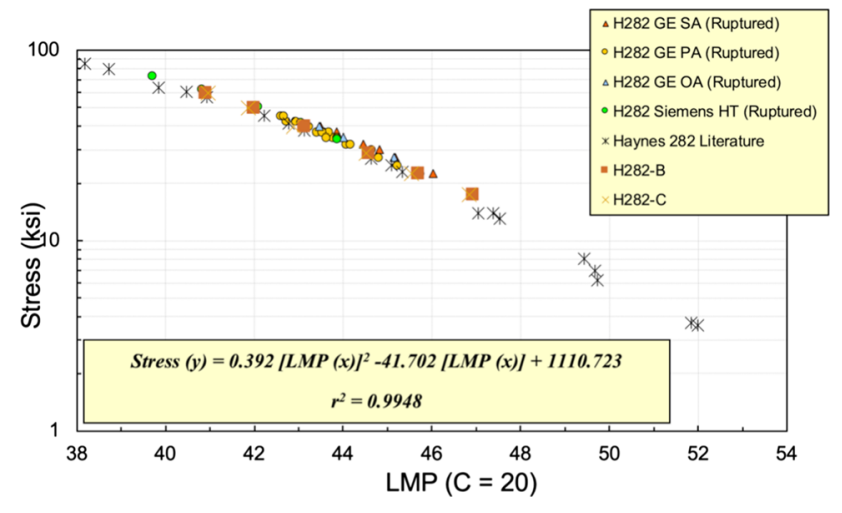

Fig. 8-Creep rupture tests for alloy 282 with results from commercial heats, NETL heats (-B and $-\mathrm{C})$, and specimens in the solution heat-treated condition that contains nano-sized $\gamma^{\prime}$ precipitates (SA), peak aged (PA), and overaged (OA). Some of the data shown have been sourced from Refs. 129, 130.

nano-sized $\gamma^{\prime}$ precipitates). As such, work was initiated to see if the two-step aging condition could be eliminated by either a one-step aging heat-treatment or heat treatment of the components upon start-up of the power plant. The idea was to use the temperature ramp up in the power plant as a "heat-treatment in place" to coarsen the $\gamma^{\prime}$ precipitates. Application of the one-step or in place heat treatment would depend on component, stress state, and design risk.

In addition to having good creep capability (i.e., > 100,000 hour creep life at $100 \mathrm{MPa}$ at use temperature), superalloys used in AUSC power plants must also have good YS (typically $>400 \mathrm{MPa}$ minimum but greater for high stress components such as rotor and airfoils). For superalloys meeting these minimum requirements, gas and steam turbine engine components are subjected to cycling which results in high stresses arising from thermal expansion effects. This can lead to failure through a mechanism known as dwell fatigue. In practice, low cycle fatigue (LCF) resistance is a commonly used approximation of dwell fatigue resistance or specific low cycle fatigue tests with a hold-time inserted into the cycle can be used. High cycle fatigue (HCF) resistance for airfoils is also very important. Fatigue crack growth rate (FCGR) at AUSC temperatures is also critical for evaluating the potential of superalloys for energy applications. ${ }^{[131-133]}$

Several superalloy compositions have been studied over the years and continue to be investigated for AUSC applications. However, the main focus has revolved around the alloys listed in Table IV. These alloys have been investigated for use as rotors, tubing (such as main piping, superheater or reheater tubes in steam boilers), airfoils, and other ancillary components. Alloys 740/ $740 \mathrm{H}, 617 / \mathrm{CCA} 617$, and 230 have been considered for tubing/piping (and certified through ASME for pressure vessel usage). CCA617 (controlled chemistry version) is a variant of alloy 617 developed for increased strength through the precipitation of the $\gamma^{\prime}$ precipitates and controlled B content as well as grain size. ${ }^{[134]}$ Superalloy 282 has shown great potential as a rotor but is also being considered for use in boiler components (and is in the process of having an ASME pressure vessel code case developed), while 263 has been considered a back-up for 282 in cast form. High-strength alloys that cannot be welded easily (e.g., 105 and Waspaloy) have been investigated as airfoils and bolting, among other smaller components. ${ }^{[127]}$

The service life of critical components in AUSC power plants is a major driver for selection, which is related to the creep-rupture strength. However, other properties are essential to AUSC component development, such as fabricability, weldability, phase stability, oxidation/corrosion resistance, tensile, and fatigue properties. Some of the essential factors are discussed in the following sections.

\section{B. Service Life}

The service conditions of the next-generation AUSC power plants will require main component life $\geq 100,000$ hours with temperatures $\geq 750^{\circ} \mathrm{C}$ and pressures $\geq 35$ $\mathrm{MPa} \cdot{ }^{[125,129,134,135]}$ As such it is imperative to investigate failure mechanisms for potential rotor alloys including under creep and fatigue loading conditions as they pertain to the power plant cycle. Especially important is the effect of creep on fatigue crack growth. At high temperatures $\left(T>0.3 T_{\text {melt }}\right)$, thermally activated, time-dependent mechanisms may influence mechanical behavior. With a melting range around $1300^{\circ} \mathrm{C}$ for 
Table IV. List of Candidate Superalloys for AUSC Power Plants

\begin{tabular}{lllll}
\hline Alloy & Component & & \multicolumn{1}{c}{ Advantage } & Disadvantage \\
\hline 105 & blades/bolts & creep strength & weldability & seferences \\
230 & tubing/piping & welding & size limitation & 134,135 \\
263 & rotor (low T) & weldability, ductility & strength & 134,136 \\
282 & rotor (high T) & strength, fabricability & strength & 136 \\
617 & tubing/piping & creep, oxidation & strain-age cracking & 136 \\
CCA617 & tubing/piping & creep, oxidation & strength & 135 \\
625 & rotor (low T) & oxidation & phase stability & 134 \\
740 & tubing/piping & corrosion, fabricability, welding & $134,136,137$ \\
$740 \mathrm{H}$ & tubing/piping & strength, corrosion, fabricability, welding & & 136 \\
Waspaloy/R-41 & blades/bolts & strength & weldability, ductility & 134,136 \\
\hline
\end{tabular}

superalloys targeted for AUSC turbine rotors, service conditions call for homologous temperatures up to $T /$ $T_{\text {melt }} \approx 0.66$. In AUSC turbine applications, for example, time-dependent, visco-plastic creep damage and oxidation damage are significant concerns. Long-term creep may affect the fatigue crack growth mechanism in three ways: (i) microstructural changes (i.e., precipitate coarsening, chemical diffusion), (ii) stress relaxation (i.e., diffusion enhanced dislocation motion), and (iii) creep crack growth (i.e., nucleation and coalescence of vacancies ahead of a growing crack). Similarly, oxidation may affect the fatigue crack growth via mechanisms such as stress-assisted grain boundary oxidation or embrittlement. Either situation may lead to the local microstructure ahead of the crack tip evolving during exposure at AUSC temperatures and pressures, potentially changing the fatigue crack propagation mechanism and altering the crack growth rate. ${ }^{[131-133]}$

A requirement for AUSC boiler material has been generally defined as 100,000 hours of life in creep at a stress level of $100 \mathrm{MPa}$ at the targeted operating temperature. ${ }^{[138]}$ This has been extended to steam turbine materials alongside YS requirements. Figure 9 compiles suitable energy alloy classes and specific superalloys as a function of their 100,000 hour creep-rupture stress versus operating temperature. Ferritic (9 to 12 pct $\mathrm{Cr}$ ) steels can operate at temperatures below $650{ }^{\circ} \mathrm{C}$ and are essential in limiting the overall power plant cost. At higher temperatures and at low stresses, austenitic steels can be used as they meet requirements in strength and oxidation/corrosion resistance. However, their operating temperature is less than, or limited to, $700{ }^{\circ} \mathrm{C}$. In many instances, component dimension can be adjusted to meet stress and creep life requirements.

Beyond an operating temperature of $\sim 700{ }^{\circ} \mathrm{C}$, it is necessary to use superalloys particularly when high stresses are present. Their use is thus limited to the hottest sections of the boiler and steam turbine to minimize plant material's costs. The 100,000 creep life in hours at $100 \mathrm{MPa}$ is met around $720^{\circ} \mathrm{C}$ for 617 and 230 and near $800{ }^{\circ} \mathrm{C}$ according to predictions for Waspaloy and $105 \cdot{ }^{[134]}$ Superalloys $740 \mathrm{H}$ and 282 fall in between with creep temperature capability above $760{ }^{\circ} \mathrm{C}$, the target operating temperature for AUSC power plants in the United States.

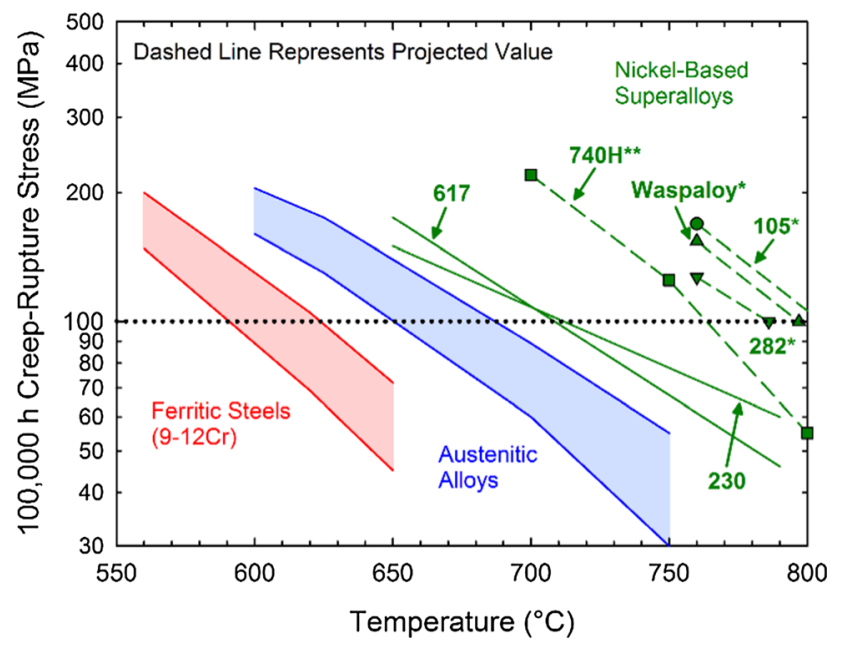

Fig. 9-100,000 h creep-rupture stress for structural material candidates for AUSC power plants with target and ongoing research goals. Adapted from Ref. 134 with $(*)$ data obtained from LMP correlations and $(* *)$ obtained from Ref. 139

\section{Phase Stability}

Extended service life is associated with great phase stability of the superalloy. For instance, the precipitation of undesirable intermetallic phases, such as TCP phases that form after extended time at temperature, is detrimental and known to deprive the matrix of elements used for solid solution strengthening. TCP phases can also serve as crack initiation sites. Superalloy $740 \mathrm{H}$ is a perfect example as its chemistry was optimized from the initial 740 chemistry for application in AUSC power plants partly to improve its phase stability. ${ }^{[137]}$ Formation of $\mathrm{G}$ phase was eliminated by reducing the $\mathrm{Si}$ concentration. Furthermore, precipitation of the undesirable $\eta-\mathrm{Ni}_{3} \mathrm{Ti}$ phase was prevented by decreasing $\mathrm{Ti}$ and increasing Al which stabilized $\gamma^{\prime}$ (Figure 5). As illustrated in Figures 10(a) and (b), $\eta$ formation was not observed after 5000 hours at $750{ }^{\circ} \mathrm{C}$ in $740 \mathrm{H}$, while needle-like $\eta$ precipitates formed along the grain boundaries of 740. Thermo-Calc simulations using the TTNi8 database further illustrate the stability of the $\gamma^{\prime}$ in $740 \mathrm{H}$ (see Figure 10(d)), as opposed to the $\eta$ phase in 740, Figure 10(c). Although Shingledecker et al. ${ }^{[140]}$ showed that the formation of $\eta$ did not strongly influence the creep-rupture strength, it has been shown that the 

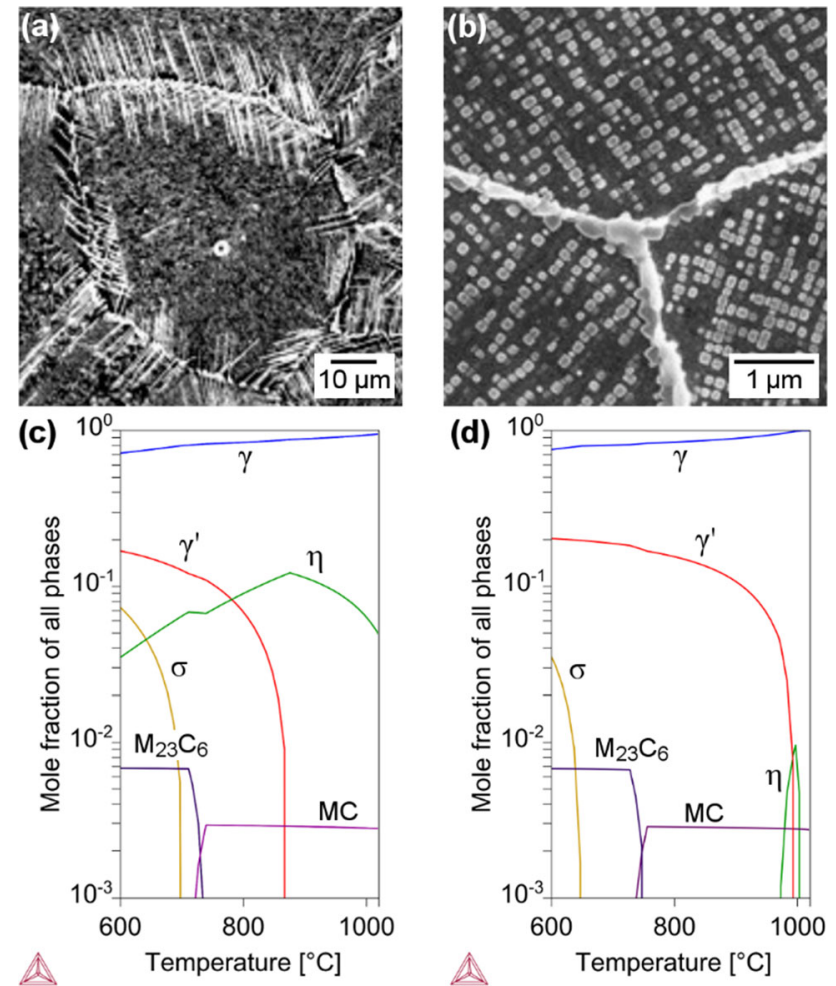

Fig. 10-Micrographs after $5000 \mathrm{~h}$ exposure at $750{ }^{\circ} \mathrm{C}$ in (a) 740 and $(b) 740 \mathrm{H}$ with respective Thermo-Calc predictions between 600 ${ }^{\circ} \mathrm{C}$ and $1000{ }^{\circ} \mathrm{C}$ using the TTNi8 database $(c$ and $d)$. Micrographs are reprinted with permission from Ref. 142. This chapter is distributed under the terms of the Creative Commons Attribution License (http://creativecommons.org/licenses/by/3.0), which permits unrestricted use, distribution, and reproduction in any medium, provided the original work is properly cited.

precipitates degraded impact toughness and thus the $740 \mathrm{H}$ variant was more desirable for AUSC applications. ${ }^{[141]}$

Another important factor associated with phase stability is the coarsening of $\gamma^{\prime}$, which affects the long-term mechanical properties of the alloys, and as such, service life. Investigations utilizing phase field modeling examined $\gamma^{\prime}$ coarsening as well as the effect of $\gamma / \gamma^{\prime}$ lattice misfit in $282 .^{[143-145]}$ Results showed that misfit and $\mathrm{Al} / \mathrm{Ti}$ ratio were important considerations when optimizing 282 chemistry for long-term AUSC applications. Well investigated alloys, such as 282 , have long-term experimental data available, e.g., Pike ${ }^{[146]}$ adapted in Figure 11. The alloy was exposed to $649^{\circ} \mathrm{C}$ or $760{ }^{\circ} \mathrm{C}$ for times up to 16,000 hours and tensile tested at the exposure temperature. Very little variation in YS was observed for exposure/deformation at $649^{\circ} \mathrm{C}$ while the elongation slightly decreased up to 4000 hours exposure, thereafter remaining relatively constant at longer times. Results at $760{ }^{\circ} \mathrm{C}$ were promising, showing a slight decrease in YS with the superalloy retaining 86 pct of its original YS after 16,000 hours exposure with no ductility concerns.

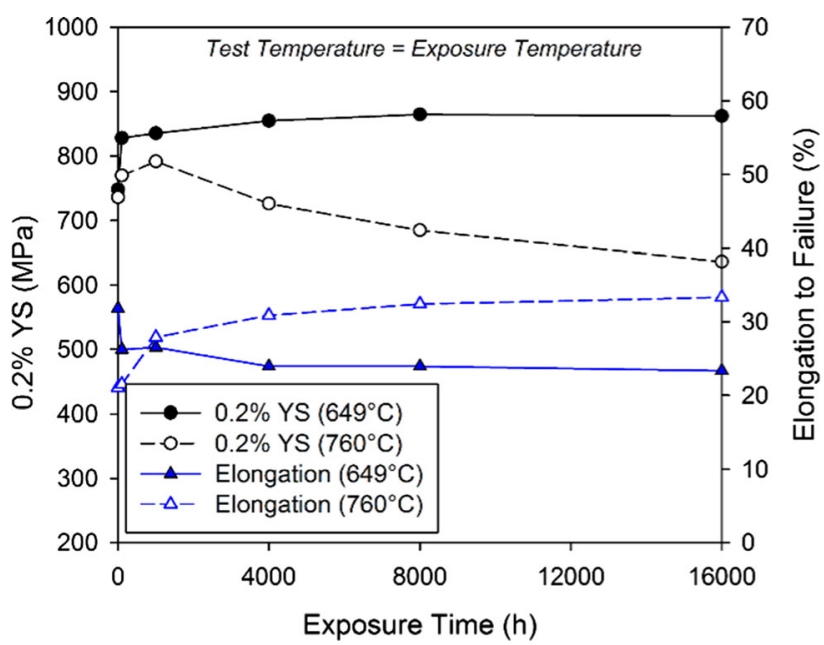

Fig. 11-Tensile YS and elongation to failure for 282 exposed for times up to $16,000 \mathrm{~h}$ at $649^{\circ} \mathrm{C}$ and $760^{\circ} \mathrm{C}$ prior to testing. Adapted from data in Ref. 146.

\section{Power Plant Component Sizes and Geometries}

AUSC power plants require the manufacturing of Ni-based superalloys in geometries and sizes that are far larger than those generally used in aircraft-based applications. Two main categories are described in the following subsections.

\section{Tubing/Piping for AUSC Boilers}

One of the major breakthroughs in the development of alloys for AUSC application is $740 \mathrm{H}$ development as the primary AUSC hot section boiler material for components. The $740 \mathrm{H}$ superalloy possesses excellent hot corrosion resistance for fireside items as well as very good oxidation resistance on the steam side use for main-steam headers, pipes and tubes. With outer diameter up to $760 \mathrm{~mm}$ (i.e., steam reheat piping) and wall thicknesses in excess of $38 \mathrm{~mm},{ }^{[139]}$ the pipe size challenges fabrication of AUSC components. DeBarbadillo et al.$^{[137]}$ described the development of $740 / 740 \mathrm{H}$ for AUSC application with the need for large size ingots to produce tubing/piping. In 2005, a 500-mm-diameter VIM and ESR ingot of alloy 740 was made as part of the COMTES700 project and successfully processed into tube. Later on, in 2013, a $750 \mathrm{~mm}$ VAR ingot was produced at Special Metals Huntington in West Virginia. The ingot, with reported weight of $7570 \mathrm{~kg}$, is represented in Figure 12a. One of the key factors in the production of large ingots is to avoid segregation through process control and homogenization optimization. ${ }^{[147]}$

Additional challenges need attention from the ingots to extrusion into tubes which are mostly related to surface quality and flow stress of the alloy. Alloys $740 \mathrm{H}$, 263, and 617 have been successfully processed into tubes. Large pipes for headers were extruded at Wyman-Gordon in Houston Texas measuring $378 \mathrm{~mm}$ in diameter, $88 \mathrm{~mm}$ in wall thickness, and $8.9 \mathrm{~m}$ length. ${ }^{[148]}$ Alloy $740 \mathrm{H}$ has been most successful in its extrusion capability as it produced lower flow stresses during hot working as compared to 263 and 617. Above 

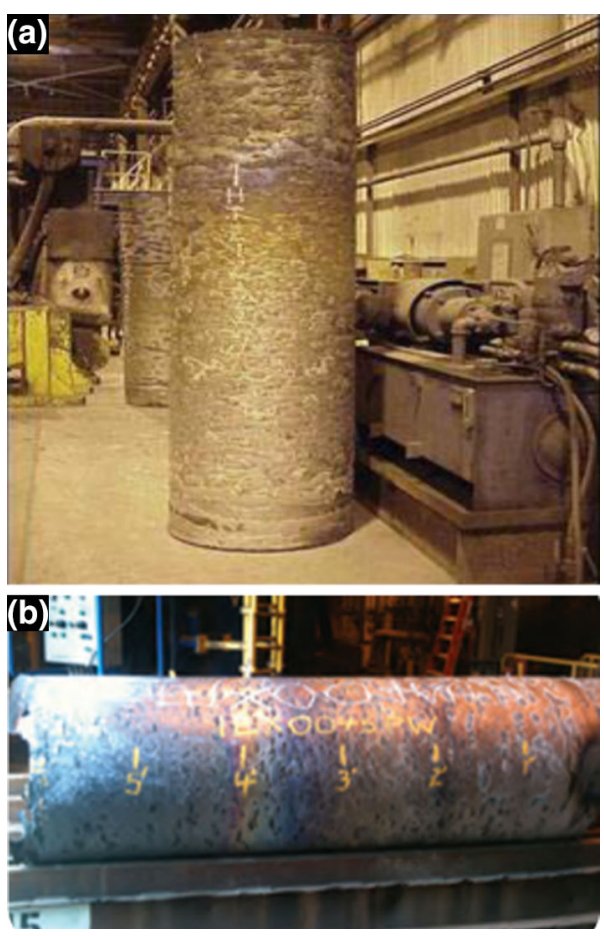

Fig. 12-(a) 750-mm-diameter VAR ingot of alloy $740 \mathrm{H}$ at Special Metals, Huntington WV and (b) 600-mm-diameter triple melted (VIM/ESR/VAR) ingot of alloy 282. Reprinted with permission from Ref. 137, 151

the $\gamma^{\prime}$ solvus temperature, refractory elements impart most of the strength of the alloy from solid solution strengthening. From Table III, alloy $740 \mathrm{H}$ has $1.6 \mathrm{wt}$ pct $(\mathrm{Mo}+\mathrm{Nb})$, while alloys 263 and 617 contain 6 and 9 wt pet Mo, respectively, making them more difficult to hot work.

The tubes/pipes also need to be bendable. Bending of small tubes can be performed at room temperature; however, this has been successful on alloy $740 \mathrm{H}$ after solution anneal and not aged condition, causing issues with the code cases since the microstructure, and thus mechanical properties, are affected. ${ }^{[149]}$ Furthermore, additional solution annealing is required following cold work past a certain strain range to avoid degradation of the creep properties. ${ }^{[150]}$ Larger diameter components such as header and re-heater pipes require hot induction bending to alleviate the stresses involved during deformation.

\section{Rotors for AUSC Steam Turbines}

Rotor forgings are critical parts of steam turbines as they will be exposed to the $760{ }^{\circ} \mathrm{C}$ steam inlet temperature for extended time at pressures up to $35 \mathrm{MPa}$. Indeed, the rotor is the largest wrought item in the steam turbine and typically the most expensive. The high- and intermediate-temperature cast rotor ingots in steam turbines can easily be $>35,000 \mathrm{~kg}$ (current VIM-VARESR ingot size is $\sim 4500 \mathrm{~kg}$, so any steam turbine rotor would need to be made of segments much like current GT rotors). Candidate alloys for rotor forgings include alloys 105, 263, 282, 625, and 718 depending on the program. While the fabrication process is similar to some used in the aerospace industry such as triple melting, i.e., VIM/ESR/VAR, the size of the component once again adds challenges. Avoiding segregation in the ingot, as mentioned in the previous subsection, remains a key factor to the development of large rotor forgings. Fabricability is also essential to reduce the risk of cracking during forging. Alloys 263 and 282 have been preferred candidates for rotor forgings, particularly 282 which were triple melted into a $600 \mathrm{~mm}$ diameter ingot represented in Figure 12b.

In order to make rational selections of candidate alloys for a high-pressure steam turbine rotor, some minimum criteria are needed. In the NETL/DOE AUSC program, creep rupture life at $760{ }^{\circ} \mathrm{C}$ for 100,000 hours, YS at $760{ }^{\circ} \mathrm{C}$, and room temperature fracture toughness were selected as critical rotor screening mechanical properties. Table $\mathrm{V}$ contains the target minimum values for these material property CTQs (critical to quality). ${ }^{[129]}$

For most rotor applications, rupture strength of at least $100 \mathrm{MPa}$ at 100,000 hours is necessary at the operational temperature. Ideally, rupture strength of $100 \mathrm{MPa}$ at 250,000 hours is desirable. Most nickel superalloys are not tested to obtain estimates of creep life at the stresses required for rotors in a steam turbine.

Most precipitate strengthened nickel superalloys can meet the YS and fracture toughness criteria. For example, the 105,282 , and $740 / 740 \mathrm{H}$ superalloys meet these criteria as do many others. When section size, fabricability, weldability, etc. are considered many of the other possible alloys, including the 105 alloy, drop out. Also, many of the high strength $\gamma^{\prime \prime} / \gamma^{\prime}$ alloys like $901,706,718$, etc. do not have adequate creep strength at $760^{\circ} \mathrm{C}$ to meet, or even come close to, the 100,000 hour creep rupture strength requirement of $100 \mathrm{MPa}$.

Little mention has been made to the fatigue and creep fatigue of nickel superalloys for steam power plants. In general, much has been learned about nickel superalloys through their incorporation in gas turbine (GT) technology, both in aero-engines and large land-based systems. Typically, steam turbines have been considered as base-load systems, meaning they are meant to operate for long periods of time between service and inspection. As such the number of cycles a steam turbine was expected to see in its lifetime was around 10,000 or so. With the widespread introduction of renewable energy sources in the grid, primarily wind and solar, and with the explosion of land-based and smaller modular GT systems, steam power plants are now envisioned to cycle more frequently depending on grid need rather than providing the base. As such, these plants of the near future may easily cycle more than 100,000 times in their life, or to put it another way, the number of cycles a cycling steam power plant undergoes may now well define its life.

Figure 13 shows the low cycle fatigue of several $\gamma^{\prime}$ precipitate strengthened nickel superalloys as well as alloy 617 at $750{ }^{\circ} \mathrm{C}$ and $760{ }^{\circ} \mathrm{C}$. Generally speaking, there is little difference (outside of the usual scatter in fatigue testing) among these alloys at the AUSC temperature. The main takeaway is that low cycle fatigue testing will need to be extended to well beyond 


\begin{tabular}{llc}
\multicolumn{1}{c}{ Metric } & Units & $\begin{array}{c}\text { Target } \\
\text { Minimum }\end{array}$ \\
rupture stress at LMP $=25.83(\mathrm{C}=20)$ & $\mathrm{MPa}$ & 100 \\
& $\mathrm{MPa}$ & 415 \\
steam inlet temperature & $\mathrm{MPa} \cdot \sqrt{\mathrm{m}}$ & 55 \\
body radial $K_{\mathrm{ic}}$ &
\end{tabular}

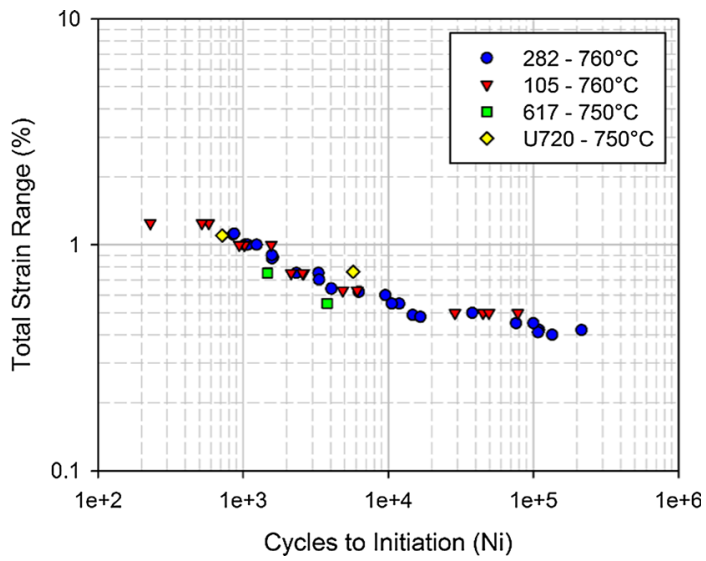

Fig. 13-Low-cycle fatigue properties for candidate alloys $(R=0$ and -1.0$)$.

100,000 cycles to minimize risk. More importantly, however, dwell or hold-time testing will be needed to better understand the effect of cycling on the long-term life of these machines. Some work on the 282 alloy has been performed but all alloys in the steam power plant will need to be investigated to see if more frequent cycling in the presence of the steam environment at AUSC (and even USC temperatures) affects life in a detrimental way. ${ }^{[131-133]}$ These hold-time tests are expensive and time consuming because to do them well, i.e., to make them reflective of the actual cycling condition, requires a hold-time commensurate with service load cycle. In the most simplistic sense, if the power plant cycles on for 12 hours and then off for 12 hours, the hold-time would be 12 hours. As such, you have the cycle superposed on a creep test broken up in 12 hour increments. Once a crack is initiated, then the environment begins to play a factor in the propagation of the crack. So not only is the hold-time information important but the crack growth behavior becomes critical in terms of the hold-time.

\section{E. Weldability}

In energy applications, there will almost certainly be some Ni-alloy components that will need to be welded such as flanges, valve bodies, and headers. ${ }^{[125,135,137]}$ According to Andersson, ${ }^{[152]} \mathrm{Ni}$-alloy welding issues can be broken down into two broad classifications: Geometrical and Metallurgical. The geometrical issues include the shape of the weld pool (tear drop tending to be more crack prone), location of the weld (concave

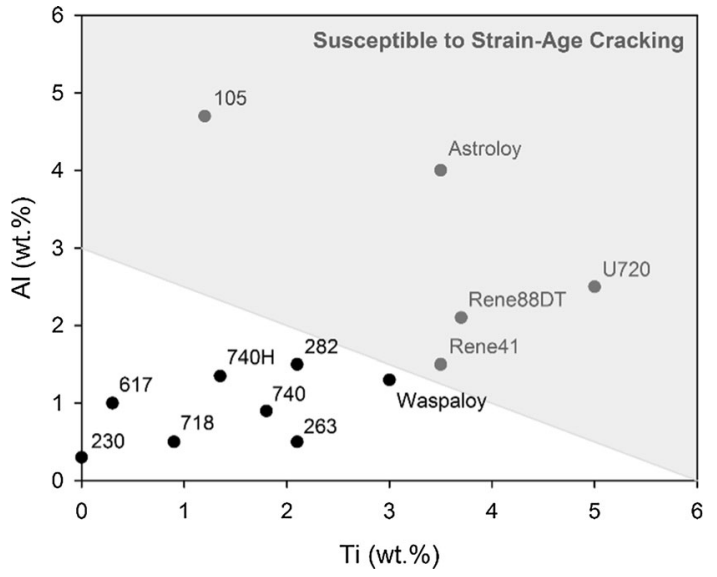

Fig. 14- Ti/Al ratio for selected alloys with susceptibility for strain-age cracking (adapted from Refs. 188, 189 and with added AUSC candidate alloys).

tending to be more crack prone), as well as residual stress and weld defects. ${ }^{[152]}$ The metallurgical issues mainly include strain age cracking (SAC) and hot cracking. Strain age cracking can result from the stresses induced by thermal expansion/contraction strains and the quick precipitation kinetics of $\gamma^{\prime}$ in the heat affected zone and weld pool. ${ }^{[153-157]}$ As such, limitations on the amount of $\gamma^{\prime}$ by limiting the $\mathrm{Al}+\mathrm{Ti}$ to less than six atomic percent have been found to be helpful. ${ }^{[153,158]}$ In addition, adjusting the $\mathrm{Ti} / \mathrm{Al}$ ratio to be $>2$ (weight percent basis), or according to the plot of Figure 14, slows the $\gamma^{\prime}$ kinetics sufficiently to avoid SAC in many cases. ${ }^{[153]}$ Hot cracking can occur in the weld itself and can be characterized as a solidification hot tear, which can be influenced by the alloy, weld contamination, and weld geometry. ${ }^{[159-172]}$ Nickel alloys tend to have a wide solidification range and the wider the range, the more prone the alloy is to hot tear defects. Hot cracking can also occur in the heat-affected zone (HAZ). Typically, this can be caused by constitutional liquation of grain boundary phases or segregated melt point depressants such as B, C, S, and P..$^{[161,173-187]}$ In both forms, a liquid is formed on the grain boundary in the HAZ, reducing the local strength and ductility to zero. By its nature, liquation cracking is exacerbated by the rapid heating associated with welding. These concerns combine to make welding a major issue for the application of Ni-alloys in energy applications. 


\section{F. Oxidation}

The environmental challenges facing Ni-alloy components in energy applications are quite diverse. ${ }^{[123,188]}$ The gases involved might include air, steam, or $\mathrm{CO}_{2}$, each of which might include significant contaminants of $\mathrm{SO}_{4}{ }^{-}$, $\mathrm{Cl}$, and others. ${ }^{[125,190]}$ In boiler and gasifier applications, the components could be exposed to slags of such diverse and aggressive chemistries as to make Calcium-Magnesium-Aluminosilicate (CMAS) exposure look inviting. ${ }^{[125,190]}$ Due to some of the welding issues discussed above, most if not all of the Ni-alloys under consideration for energy applications have Al contents too low to be alumina formers under typical power plant operating conditions. As a result, typical $\mathrm{Cr}$ contents are about $22 \mathrm{wt}$ pct in order to ensure the formation of a stable chromia scale.

\section{G. Concluding Remarks}

It is not possible in an overview of this nature to address every issue of importance in the field. For example, thick-wall nickel castings were not discussed. However, it should be noted that in coal-fired power plants many components are cast including valve chest and rotor casings as well as some of the larger thick-wall boiler components. While the history of nickel castings is long and rich, thick-wall $\gamma^{\prime}$ precipitate castings have not been developed to the same extent as other thin-wall cast items and much work was required in the DOE/ NETL AUSC program to address this issue.

Before the advent of research on AUSC materials for power plants, nickel superalloys mainly served in strength-specific roles in supercritical (SC) and ultra supercritical (USC) steam power plants while providing much of the hardware in land-based GT power plants. For example, bolting for items in the steam turbine is usually handled with alloy 718 (high YS). Valve stems for certain steam turbine designs have been made from alloy 901 (superior creep life compared to 9 pct Cr steel). More recently, airfoil designs have changed for efficiency concerns and as such nickel superalloy is used in the first row (maybe the first two, depending on steam inlet design configuration) of the high-pressure steam turbine (stress relaxation) instead of 9 to 12 pct $\mathrm{Cr}$ steel. $^{[191]}$

Additionally, discussion on current gas turbine technology was limited not because it is not important but because the literature contains copious information on the evolution of this technology. One point that needs to be mentioned is why alloys such as 706,718 , and $625+/$ 725 have not been discussed in terms of AUSC technology. Part of issue with these alloys is the stability of $\gamma^{\prime \prime} / \gamma^{\prime}$ at the temperatures of interest. ${ }^{[192-194]}$ While these alloys have excellent YS and UTS at temperatures up to and including $700^{\circ} \mathrm{C}$, their creep life at these temperatures degrades quickly as the microstructure evolves. With that said, it is a relevant concern and research continues in stabilizing the $\gamma^{\prime \prime} / \gamma^{\prime}$ precipitates at higher temperatures so alloys of this type can be used in AUSC power plants.
As mentioned in the narrative, the difficulties associated with machining nickel superalloys as well as producing thick section welds is key in using these alloys in steam power plants. As such other technologies are being explored to understand the limits of the technology with respect to $\gamma^{\prime}$ strengthened nickel superalloys like friction stir processing as a joining/repair technology for castings and thick-wall items or additive manufacturing as a processing technology to build up smaller components (at this time) or possibly offer other auxiliary manufacturing options like transition sections between dissimilar alloys.

Nickel superalloys exist that can be used to construct AUSC power plants, but much work is needed to make them affordable. For example, associated lower temperature alloys in the boiler and steam turbines need improvement in terms of their temperature capability so as to minimize the quantity of nickel superalloy used in the plant. It is also important to produce a robust supply chain for these alloys and part of that effort includes looking at other nickel superalloys and improving their temperature capability both in the as-cast and cast/ wrought forms so multiple vendors can supply material for construction.

\section{SUMMARY}

This paper reviews the status of technology in design and manufacture of new wrought polycrystalline Ni-base superalloys for critical engineering applications. From the aerospace sector, the development of new powder metallurgy and ingot metallurgy alloys have been discussed for disk rotor and static applications. New compositions for powder metallurgy contain about 50 to 55 pct of gamma prime $\left(\gamma^{\prime}\right)$ strengthening precipitates to ensure components operate successfully at temperatures up to $788^{\circ} \mathrm{C}\left(1450{ }^{\circ} \mathrm{F}\right)$. In contrast, new compositions for ingot metallurgy aim to occupy a design space in temperature capability between Alloy 718 and current powder alloys that are in-service, and show levels of $\gamma^{\prime}$ of about 30 to 44 pct. The focus in developing these alloys was design for manufacturability. To complement the aerospace developments, a review of work to understand the suitability of candidate alloys for multiple applications in Advanced-Ultra Supercritical (AUSC) power plants has been undertaken. In these power plants, steam temperatures are required to reach $700{ }^{\circ} \mathrm{C}$ to $760^{\circ} \mathrm{C}$. The common thread is to develop alloys that demonstrate a combination of high-temperature properties, which are reliant on both the alloy composition and microstructure and can be produced readily at the right price. For the AUSC applications, the emphasis is on high-temperature strength, long-term creep life, phase stability, oxidation resistance, and robust welding for fabrications. Whereas for powder disk rotors in aircraft engines, the priority is enhanced resistance to time-dependent crack growth, phase stability, and resistance to environmental damage while extending the current strength levels, which are shown by existing alloys, to higher temperatures. 


\section{ACKNOWLEDGMENTS}

Dr Hardy would like to thank Rolls-Royce ple for permission to publish section 1 of this paper and for interesting and fruitful discussions with colleagues at Rolls-Royce and the Rolls-Royce UTC at the Universities of Birmingham, Cambridge, Oxford and Swansea.

\section{APPENDIX}

\section{Yield Stress Model}

It is worth noting that the fast acting Parthasarathy mode $^{[11]}$ is a fit to the parametric studies of discrete dislocation simulations (DDS) of Rao et al. ${ }^{[15]}$ The model breaks down the cumulative effect of strengthening in the structure due to $\gamma$ and $\gamma^{\prime}$ grains in order to cover both cases when the modeled alloy is sub-solvus or super-solvus solution heat treated. The effect of CRSS is a combination of friction stress, APB energy, precipitate size, coherency, and temperature for mixed type dislocations.

The friction stress $\left(\tau_{\gamma^{\prime}}\right)$ takes the following form as shown in Kozar ${ }^{[12]}$ and by employing the Roth ${ }^{[16]}$ and Mishima $^{[17]}$ solid solution strengthening coefficients. The polynomial expression at the end of Eq. [1] allows the model to capture the anomalous yield behavior of Ni-superalloys at elevated temperatures $(T)$ due to dislocation cube slip rather than octahedral.

$$
\begin{aligned}
\tau_{\gamma^{\prime}}= & \tau_{\partial \gamma^{\prime}}+\left[\sum_{\text {all solutes }}\left(\delta \tau / \partial C_{\text {solute, } \gamma^{\prime}}\right) C_{\text {solute } \gamma^{\prime}}\right] \\
& +\left[q_{1} T+q_{2} T^{2}+q_{3} T^{3}+q_{4} T^{4}\right]
\end{aligned}
$$

where $\tau_{o \gamma^{\prime}}$ is the friction stress of pure $\mathrm{Ni}, \mathrm{C}_{\text {solute } \gamma^{\prime}}$ is the concentration of solute in $\gamma^{\prime}$, and $q_{1}$ to $q_{4}$ are fitting parameters. A similar expression is defined for the $\gamma$ phase where now the temperature dependence follows a decaying power law.

$$
\tau_{\gamma}=\tau_{o \gamma}+(k 1 / T)^{k 2}\left[\sum_{\text {all solutes }}\left(\delta \tau / \partial C_{\text {solute }, \gamma}^{0.5}\right) C_{\text {solute }, \gamma}^{0.5}\right]
$$

where $k 1$ and $k 2$ are fitting parameters. The effect of temperature on APB energy $\left(\Gamma_{A P B}\right)$ follows an exponential description of the form:

$$
\Gamma_{\mathrm{APB}}=\Gamma_{o} \exp \left(-T / T^{*}\right)
$$

where $\Gamma_{o}$ is the APB energy at absolute zero Kelvin $\left(T^{*}\right)$. It is then employed in the CRSS as one of the multiplication terms with a linear contribution. Similarly the effect of misfit strain in the CRSS is embedded as a polynomial function of the APB energy. The 0.3 pct misfit strain is taken as a normalization value from the initial DDS results of Rao ${ }^{[15]}$

$$
\left(c_{1}+c_{2} \Gamma_{\mathrm{APB}}-c_{3} \Gamma_{\mathrm{APB}}^{2}-c_{4} \Gamma_{\mathrm{APB}}^{2}\right)\left(\varepsilon_{\mathrm{COH}} / 0.003\right)
$$

The effect of volume fraction (of intra-granular populations) and precipitate size are power-law expressions of the form:

$$
\begin{gathered}
\sqrt{q f_{\gamma^{\prime}}} \\
S_{1}\left[a\left(f_{\gamma^{\prime}}^{-0.5}-1\right)\right]^{-S_{2}}
\end{gathered}
$$

where $f_{\gamma^{\prime}}$ and $q, S 1, a$, and $S 2$ are fitting parameters.

Finally CRSS is derived as second-order polynomial expression of the particle friction stress and a power law of the matrix friction stress multiplied by Eqs. [3-6]. The results are consistent with the typical strong/weak pair coupling equations that have been employed by Reppich. ${ }^{[10]}$ Due to the fitting form selected for the equations, they can be applied robustly in a spreadsheet as intended by the authors with direct plotting of alloying and microstructure effects.

\section{REFERENCES}

1. P. Argüelles, J. Lumsden, M. Bischoff, D. Ranque, P. Busquin, S. Rasmussen, B.A.C. Droste, P. Reutlinger, R. Evans, R. Robins, W. Kröll, H. Terho, J.-L. Lagardère, A. Wittlöv, and A. Lina: European Aeronautics: A Vision for 2020 (Advisory Council for Aviation Research and Innovation in Europe). https://www.acare 4europe.org/sites/acare4europe.org/files/document/Vision \%2020 20_0.pdf. Accessed 10 Jan 2020.

2. M. Darecki, C. Edelstenne, T. Enders, E. Fernandez, P. Hartman, J.-P. Herteman, M. Kerkloh, I. King, P. Ky, M. Mathieu, G. Orsi, G. Schotman, C. Smith, and J.-D. Worner: Flightpath 2050 Europe's vision for aviation (European Commission). http s://ec.europa.eu/transport/sites/transport/files/modes/air/doc/flig htpath2050.pdf, https://doi.org/10.2777/50266. Accessed 10 Jan 2020.

3. R.C. Reed, A. Mottura, and D.J. Crudden: in Superalloys 2016 , M. Hardy, E. Huron, U. Glatzel, B. Griffin, B. Lewis, C. Rae, V. Seetharaman, and S. Tin, eds., TMS, Warrendale, PA, USA, 2016, pp. 15-23.

4. R.J. Mitchell, J.A. Lemsky, R. Ramanathan, H.Y. Li, K.M. Perkins, and L.D. Connor: in Superalloys 2008, R.C. Reed, K.A. Green, P. Caron, T. Gabb, M.G. Fahrmann, E.S. Huron, and S.A. Woodard, eds., TMS, Warrendale, PA, USA, 2008, pp. $347-56$.

5. D. Anderson: Fuel Conservation Operational Procedures for Environmental Performance (International Civil Aviation Organisation) https://www.icao.int/Meetings/EnvironmentalWo rkshops/Documents/ICAO-TransportCanada-2006/Anderson_o ps.pdf. Accessed 10 Jan 2020

6. R.L. Dreshfield and H.R. Gray: NASA, TM-83623, Lewis Research Center, Cleveland, 1984.

7. R. Anderson: Int. J. Powder Metall., 1990, vol. 26 (2), pp. 171-78.

8. J. Smythe: Advanced Materials and Processes, 2008, November, pp. $52-55$.

9. J. Gayda and D. Furrer: Heat-Treating Progress, 2003, September/October, pp. 85-89.

10. B. Reppich: Acta Metall., 1982, vol. 30, pp. 87-94.

11. T.A. Parthasarathy, S.I. Rao, and D.M. Dimiduk: in Superalloys 2004, K.A. Green, T.M. Pollock, H. Harada, T.E. Howson, R.C. Reed, J.J. Schirra, and S. Walston, eds., TMS, Warrendale, PA, USA, 2004, pp. 887-96.

12. R.W. Kozar, S. Suzuki, W.W. Milligan, J.J. Schira, M.F. Savage, and T.M. Pollock: Metall. Mater. Trans. A, 2009, vol. 40A, pp. $1588-1603$.

13. D.J. Crudden, A. Mottura, N. Warnken, B. Raeisinia, and R.C. Reed: Acta Mater., 2014, vol. 75, pp. 356-70.

14. E.I. Galindo-Nava, L.D. Connor, and C.M.F. Rae: Acta Mater., 2015, vol. 98, pp. 377-90. 
15. S.I. Rao, T.A. Parthasarathy, D.M. Dimiduk, and P.M. Hazzledine: Philos. Mag., 2004, vol. 84, pp. 3195-3215.

16. H.A. Roth, C.L. Davis, and R.C. Thomson: Metall. Mater. Trans. A, 1997, vol. 28A, pp. 1329-35.

17. Y. Mishima, S. Ochiai, M. Yodogawa, and T. Suzuki: Trans. Jpn. Inst. Met., 1986, vol. 27, pp. 41-50.

18. K.A. Christofidou, M.C. Hardy, H.Y. Li, C. Argyrakis, H. Kitaguchi, N.G. Jones, P.M. Mignanelli, A.S. Wilson, O.M.D.M. Messé, E.J. Pickering, R.J. Gilbert, C.M.F. Rae, S. Yu, A. Evans, D. Child, P. Bowen, and H.J. Stone: Metall. Mater. Trans. A, 2018, vol. 49A, pp. 3896-3907.

19. N. D'Souza, W. Li, C. Argyrakis, G.D. West, and C.D. Slater: Metall. Mater. Trans. A, 2019, vol. 50A, pp. 4205-22.

20. G.J. Davies, J.W. Edington, C.P. Cutler, and K.A. Padmanabhan: JOM, 1970, vol. 5, pp. 1091-1102.

21. M. Soucail, M. Marty, and H. Octor: in Superalloys 1996, R.D. Kissinger, D.J. Deye, D.L. Anton, M.V. Nathal, A.D. Cetel, and T.M. Pollock, eds., TMS, Warrendale, PA, USA, 1996, pp. 663-66.

22. E.S. Huron. S. Srivastsa, and E. Raymond: in Superalloys 2000, T.M. Pollock, R.D. Kissinger, R.R. Bowman, K.A. Green, M. McLean, S. Olson, and J.J. Schirra, eds., TMS, Warrendale, PA, USA, 2000, pp. 49-58.

23. T.P. Gabb, J. Gayda, and J. Falsey: NASA, TM-2005-213649, NASA Glenn Research Center, Cleveland, 2005.

24. S.L. Semiatin, J.M. Shank, A.R. Shiveley, W.M. Saurber, E.F. Gaussa, and A.L. Pilchak: Metall. Mater. Trans. A, 2014, vol. $45 \mathrm{~A}$, pp. $6231-51$.

25. V.M. Miller, A.E. Johnson, C.J. Torbet, and T.M. Pollock: Metall. Mater. Trans. A, 2016, vol. 47A, pp. 1566-74.

26. A. Agnoli, M. Bernacki, R. Logé, J.-M. Franchet, J. Laigo, and N. Bozzolo: Metall. Mater. Trans. A, 2015, vol. 46, pp. 4405-4421.

27. I.M.D. Parr, T.J. Jackson, M.C. Hardy, D.J. Child, C. Argyrakis, K. Severs, V. Saraf, and J.M. Stumpf: in Superalloys 2016, M. Hardy, E. Huron, U. Glatzel, B. Griffin, B. Lewis, C. Rae, V. Seetharaman, and S. Tin, eds., TMS, Warrendale, PA, USA, 2016, pp. 447-56.

28. R. Yoda, T. Yokomaku, and N. Tsuji: Mater. Charact., 2010, vol. 61, pp. 913-22.

29. F.J. Humphreys and M. Hatherly: Recrystallization and Related Annealing Phenomena, Elsevier Science Ltd., Oxford, 1995.

30. E.J. Payton: Characterization and Modeling of Grain Coarsening in Powder Metallurgy Nickel-Based Superalloys, The Ohio State University, Columbus, 2009.

31. N. Bozzolo, A. Agnoli, N. Souai, M. Bernacki, and R.E. Loge: 5th International Conference on Recrystallization and Grain Growth, Sydney, Australia, 2013, https://doi.org/10.4028/www.sc ientific.net/MSF.753.321.

32. M.-A. Charpagne, T. Billot, J-M. Franchet, and N. Bozzolo: in Superalloys 2016, M. Hardy, E. Huron, U. Glatzel, B. Griffin, B. Lewis, C. Rae, V. Seetharaman, and S. Tin, eds., TMS, Warrendale, PA, USA, 2016, pp. 417-26.

33. D.U. Furrer, R. Shankar, and C. White: JOM, 2003, vol. 55, pp. $32-34$

34. G.B. Olson, H.-J. Jou, J. Jung, J.T. Sebastian, A. Misra, I. Locci, and D. Hull: in Superalloys 2008, R.C. Reed, K.A. Green, P. Caron, T. Gabb, M.G. Fahrmann, E.S. Huron, and S.A. Woodard, eds., TMS, Warrendale, PA, 2008, pp. 923-32.

35. A. Powell, K. Bain, A. Wessman, D. Wei, T. Hanlon, and D. Mourer: Superalloys 2016, M. Hardy, E. Huron, U. Glatzel, B. Griffin, B. Lewis, C. Rae, V. Seetharaman, and S. Tin, eds., TMS, Warrendale, PA, 2016, pp. 189-97.

36. S.L. Semiatin, S.-L. Kim, F. Zhang, and J. Tiley: Metall. Mater. Trans. A, 2015, vol. 46A, pp. 1715-30.

37. A.J. Ardell: Acta Metall., 1968, vol. 16, pp. 511-16.

38. H.B. Aaron, D. Fainstein, and G.R. Kotler: J. Appl. Phys., 1970, vol. 41 , pp. 4404-10.

39. S.L. Semiatin, N.C. Levkulich, A.R.C. Gerlt, E.J. Payton, J.S. Tiley, F. Zhang, R.A. Mackay, R.V. Miner, and T.P. Gabb: Metall. Mater. Trans. A, 2019, vol. 50A, pp. 2289-2301.

40. C.J. Kuehmann and P.W. Voorhees: Metall. Mater. Trans. A, 1996, vol. 27A, pp. 937-43.

41. R.J. Mitchell, H.Y. Li, and Z.W. Huang: J. Mater. Process. Tech., 2009, vol. 209, pp. 1011-17.
42. R.A. Ricks, A.J. Porter, and R.C. Ecob: Acta Metall., 1983, vol. 31, pp. 43-53.

43. M.F. Henry, Y.S. Yoo, D.Y. Yoon, and J. Choi: Metall. Mater. Trans. A, 1993, vol. 24A, pp. 1733-43.

44. A. Wisniewski and J. Beddoes: Mater. Sci. Eng. A, 2009, vols. $510-511$, pp. 266-272.

45. J.M. Larson and S. Floreen: Metall. Mater. Trans. A, 1977, vol. 8 A, pp. 51-55.

46. J.R. Groh: Superalloys 1996, R.D. Kissinger, D.J. Deye, D.L. Anton, M.V. Nathal, A.D. Cetel, and T.M. Pollock, eds., TMS, Warrendale, PA, 1996, pp. 621-26.

47. F. Torster, G. Baumeister, J. Albrecht, G. Lütjering, D. Helm, and M.A. Daeubler: Mater. Sci. Eng. A, 1997, vols. 234-236, pp. 189-92.

48. R.J. Mitchell, M.C. Hardy, M. Preuss, and S. Tin: in Superalloys 2004, K.A. Green, T.M. Pollock, H. Harada, T.E. Howson, R.C. Reed, J.J. Schirra, and S. Walston, eds., TMS, Warrendale, PA, 2004, pp. 361-70.

49. T.P. Gabb, J. Gayda, J. Telesman, and P.T. Kantzos: NASA, TM-2005-213645, NASA Glenn Research Center, Cleveland, 2005.

50. R. Radis, M. Schaffer, M. Albu, G. Kothleitner, P. Pölt, and E. Kozeschnik: Acta Mater., 2009, vol. 57, pp. 5739-47.

51. A. Devaux, B. Picqué, M.F. Gervais, E. Georges, T. Poulain, and P. Héritier: in Superalloys 2012, E.S. Huron, R.C. Reed, M.C. Hardy, M.J. Mills, R.E. Montero, P.D. Portella, and J. Telesman, eds., TMS, Warrendale, PA, 2012, pp. 911-21.

52. D.M. Collins and H.J. Stone: Int. J. Plast., 2013, vol. 54, pp. 96-112.

53. T.P. Gabb, J. Gayda, P.T. Kantzos, T. Biles, and W. Konkel: NASA, TM-2001-211218, NASA Glenn Research Center, Cleveland, 2001.

54. P.R. Bhowal, E.F. Wright, and E.L. Raymond: Met. Trans. A, 1990, vol. 21, pp. 1709-17.

55. R.R. Unocic, L. Kovarik, C. Shen, P.M. Sarosi, Y. Wang, J. Li, S. Ghosh, and M.J. Mills: in Superalloys 2008, R.C. Reed, K.A. Green, P. Caron, T. Gabb, M.G. Fahrmann, E.S. Huron, and S.A. Woodard, eds., TMS, Warrendale, PA, 2008, pp. 377-85.

56. D. Locq, P. Caron, S. Raujol, F. Pettinari-Sturmel, A, Coujou, and N. Clément: Superalloys 2004, K.A. Green, T.M. Pollock, H. Harada, T.E. Howson, R.C. Reed, J.J. Schirra, and S. Walston, eds., TMS, Warrendale, PA, 2004, pp. 179-87.

57. A. Agnoli, C. Le Gall, J. Thebault, E. Marin, and J. Cormier: Metall. Mater. Trans. A, 2018, vol. 49A, pp. 4290-4300.

58. R.C. Reed, M.P. Jackson, and Y.S. Na: Metall. Mater. Trans. A, 1999, vol. 30A, pp. 521-33.

59. H.-J. Jou, G. Olsen, T. Gabb, A. Garg, and D. Miller: in Superalloys 2012, E.S. Huron, R.C. Reed, M.C. Hardy, M.J. Mills, R.E. Montero, P.D., Portella, and J. Telesman, eds., TMS, Warrendale, PA, 2012, pp. 893-902.

60. C.K. Sudbrack, S.L. Draper, T.T. Gorman, J. Telesman, T.P. Gabb, and D.R. Hull: in Superalloys 2012, E.S. Huron, R.C. Reed, M.C. Hardy, M.J. Mills, R.E. Montero, P.D. Portella, and J. Telesman, eds., TMS, Warrendale, PA, 2012, pp. 863-872.

61. A. Pineau, D.L. McDowell, E.P. Busso, and S.D. Antolovich: Acta Mater., 2016, vol. 107, pp. 484-507.

62. A.W. Mello, A. Nicholas, and M.D. Sangid: Mater. Sci. Eng., A, 2017, vol. 695, pp. 332-41.

63. H. Ghonem and D. Zheng: Fatigue Fract. Eng. Mater. Struct., 1991, vol. 14, pp. 749-60

64. H. Ghonem and D. Zheng: Fatigue Fract. Eng. Mater. Struct., 1991, vol. 14, pp. 761-68.

65. Z. Huang, C. Iwashita, I. Chou, and R.P. Wei: Metall. Mater. Trans. A, 2002, vol. 33A, pp. 1681-87.

66. J. Telesman, P. Kantzos, J. Gayda, P.J. Bonacuse and A. Prescenzi: in Superalloys 2004, K.A. Green, T.M. Pollock, H. Harada, T.E. Howson, R.C. Reed, J.J. Schirra, and S. Walston, eds.,TMS, Warrendale, 2004, pp. 215-24.

67. T.P. Gabb, J. Gayda, J. Telesman, and A. Garg: in Superalloys 2008, R.C. Reed, K.A. Green, P. Caron, T. Gabb, M.G. Fahrmann, E.S. Huron, and S.A. Woodard, eds., TMS, Warrendale, PA, 2008, pp. 121-30.

68. H.Y. Li, J.F. Sun, M.C. Hardy, H.E. Evans, S.J. Williams, T.J.A. Doel, and P. Bowen: Acta Mater., 2015, vol. 90, pp. 355-69. 
69. H.S. Kitaguchi, H.Y. Li, H.E. Evans, R.G. Ding, I.P. Jones, G. Baxter, and P. Bowen: Acta Mater., 2013, vol. 61, pp. $1968-81$

70. L. Viskari, M. Hörnqvist, K.L. Moore, Y. Cao, and K. Stiller: Acta Mater., 2013, vol. 61, pp. 3630-39.

71. G.B. Viswanathan, D.E. Mills, and M.J. Mills: Metall. Mater. Trans. A, 2019, vol. 50a, pp. 5574-80.

72. R. Jiang, D.J. Bull, D. Proprentner, B. Shollock, and P.A.S. Reed: Int. J. Fatigue, 2017, vol. 99, pp. 175-86.

73. H.E. Evans, H.Y. Li, and P. Bowen: Scr. Mater., 2013, vol. 69, pp. 179-82.

74. K.S. Chan: Metall. Mater. Trans. A, 2014, vol. 45a, pp. 3454-66.

75. L. Cimbaro, A.P. Sutton, D.S. Balint, A.T. Paxton, and M.C. Hardy: Int. J. Fract., 2019, vol. 216, pp. 87-100.

76. C.F. Miller, G.W. Simmons, and R.P. Wei: Scr. Mater., 2003, vol. 48, pp. 103-108.

77. U. Krupp, W.M. Kane, C. Laird, and C.J. McMahon: Mater. Sci. Eng., A, 2004, vols. 387-389, pp. 409-13.

78. J.L.W. Carter, N. Zhou, J.M. Sosa, P.A. Shade, A.L. Pilchak, M.W. Kuper, Y. Wang, H.L. Fraser, M.D. Uchic, and M.J. Mills: in Superalloys 2012, E.S. Huron, R.C. Reed, M.C. Hardy, M.J. Mills, R.E. Montero, P.D. Portella, and J. Telesman, eds., TMS, Warrendale, PA, 2012, pp. 43-52.

79. J. Telesman, T.P. Gabb, and L.S. Ghosn: in Superalloys 2016, M. Hardy, E. Huron, U. Glatzel, B. Griffin, B. Lewis, C. Rae, V. Seetharaman, and S. Tin, eds., TMS, Warrendale, PA, 2016, pp. $551-60$.

80. F. Shulz, H.Y. Li, H. Kitaguchi, D. Child, S. Williams, and P. Bowen: Metall. Mater. Trans. A, 2018, vol. 49a, pp. 3874-84.

81. J. Telesman, T.P. Gabb, and L.J. Ghosn: Int. J. Fatigue, 2020 , vol. 133 (105431), pp. 1-14, https://doi.org/10.1016/ j.ijfatigue.2019.105431

82. J.S. Slaney: International Symposium on Structural Stability of Superalloys, TMS, Warrendale, 1968, pp. 67-79.

83. M. Morinaga, N. Yukawa, H. Adachi, and H. Ezakil: in Superalloys 1984, M. Gell, ed., TMS, Warrendale, PA, 1984, pp. $523-532$.

84. J.-Y. Guédou, I. Augustins-Lecallier, L. Nazé, P. Caron, and D. Locq: Superalloys 2008, R.C. Reed, K.A. Green, P. Caron, T. Gabb, M.G. Fahrmann, E.S. Huron, and S.A. Woodard, eds., TMS, Warrendale, PA, USA, 2008, pp. 21-30.

85. N. Saunders, Z. Guo, X. Li, A.P. Miodownik, and J-Ph. Scillé: Superalloys 2004 K.A. Green, T.M. Pollock, H. Harada, T.E. Howson, R.C. Reed, J.J. Schirra, and S. Walston, eds., TMS, Warrendale, 2004, pp. 849-858.

86. A.S. Wilson, K.A. Christofidou, A. Evans, M.C. Hardy, and H.J. Stone: Metall. Mater. Trans. A, 2019, vol. 50A, pp. 5925-34.

87. S. Cruchley, H.E. Evans, M.P. Taylor, M.C. Hardy, and S. Stekovic: Corr. Sci., 2013, vol. 75, pp. 58-66.

88. T.D. Reynolds, D.M. Collins, N.K. Soor, S.R. Street, N. Warnken, P.M. Mignanelli, M.C. Hardy, H.E. Evans, and M.P. Taylor: Acta Mater., 2019, vol. 181, pp. 570-83.

89. S. Pedrazzini, B.S. Rowlands, A. Turk, I.M.D. Parr, M.C. Hardy, P.A.J. Bagot, M.P. Moody, E. Galindo-Nava, and H.J. Stone: Metall. Mater. Trans. A, 2019, vol. 50A, pp. 3024-29.

90. S. Antonov, M. Detrois, R.C. Helmink, and S. Tin: J. Alloys Compd., 2015, vol. 626, pp. 76-86.

91. K.R. Bain, D.P. Mourer, R. DiDomizio, T. Hanlon, L. Cretegny, and A.E. Wessman, Nickel-Base Superalloys and Components Formed Thereof, US Patent Specification US8,992,700 B2, 31 March 2015.

92. J.M. Moyer, L.A. Jackman, C.B. Adasczik, R.M. Davis and R. Forbes-Jones: in Superalloys 718, 625, 706 and Derivatives, E.A. Loria, ed., TMS, Warrendale, PA, 1994, pp. 39-48.

93. D.F. Paulonis and J.J. Shirra: in Superalloys 718, 625, 706 and Various Derivatives, E.A. Loria, ed., TMS, Warrendale, PA, 2001, pp. 13-23.

94. D.J. Bryant and G. McIntosh: in Superalloys 1996, R.D. Kissinger, D.J. Deye, D.L. Anton, M.V. Nathal, A.D. Cetel and T.M. Pollock, eds., TMS, Warrendale, PA, 1996, pp. 713-22.

95. P.W. Keefe, S.O. Mancuso, and G.E. Maurer: in Superalloys 1992, S.D. Antolovich and R. A. Mackay, eds., TMS, Warrendale, PA, 1992, pp. 487-96.
96. D. Helm and O. Roder: in Superalloys 2000, T.M. Pollock, R.D. Kissinger, R.R. Bowman, K.A Green, M. McLean, S. Olson, and J.J. Schirra, eds., TMS, Warrendale, PA, 2000, pp. 487-93.

97. G.B. Olson: Science, 1997, vol. 277, pp. 1237-42

98. C.J. Kuehmann and G.B. Olson: Mater. Sci. Tech., 2009, vol. 25, pp. $472-78$

99. E. McDevitt, R. Minisandram, and M. Garcia-Avila: in Superalloy 718 \& Derivatives: Energy, Aerospace, and Industrial Applications, E. Ott, J.R. Groh, A. Banik, I. Dempster, T.P. Gabb, R. Helmink, X. Liu, A. Mitchell, G.P. Sjoberg, X. Xie, and A. Wusatowska-Sarnek, eds., TMS, Warrendale, PA, 2018, pp. $941-56$.

100. E. A. Ott, J. Groh, and H. Sizek: Superalloys 718, 625, 706 and Derivatives, E.A. Loria, ed., TMS, Warrendale, PA, 2005, pp. 35-45.

101. R.E. Schafrik: Metall. Mater. Trans. B, 2016, vol. 47B, pp. 1505-15.

102. S. Imano, J. Sato, H. Kamoshida, T. Shibayama, and A. Ota: Mitsubishi Heavy Ind. Tech. Rev., 2015, vol. 52, pp. 32-38.

103. W.D. Cao and R.L. Kennedy: Acta Metall. Sin., 2005, vol. 18, pp. 39-46.

104. R.L. Kennedy: in Superalloys 718, 625, 706 and Derivatives, E.A. Loria, ed., TMS, Warrendale, PA, 2005, pp. 1-14.

105. R.M. Forbes Jones, and L.A. Jackman: JOM, 1999, vol. 51, pp. 27-31

106. A. Oradei-Basile, and J.F. Radavich: in Superalloys 718,625 and Various Derivatives, E.A. Loria, ed., TMS, Warrendale, PA, 1991, pp. 325-335.

107. W.D. Cao and R. Kennedy: in Superalloys 2004, K.A. Green, T.M. Pollock, H. Harada, T.E. Howson, R.C. Reed, J.J. Schirra, and S. Walston, eds., TMS, Warrendale, PA, 2004, pp. 91-99.

108. P.R. Bhowal, and J.J. Schirra: in Superalloys 718, 625, 706 and Various Derivatives, E.A. Loria, ed., TMS, Warrendale, PA, 2001, pp. 193-201.

109. E.E. Brown, R.C. Boettner, and D.L. Ruckle: in Superalloys 1972, TMS, Warrendale, PA, 1972, pp. L1-1-L-12.

110. J.A. Heaney, M.L. Lasonde, A.M. Powell, B.J. Bond, and C.M. O'Brien: in Superalloy 718 and Derivatives, E. Ott, J.R. Groh, A. Banik, I. Dempster, T.P. Gabb, R. Helmink, X. Liu, A. Mitchell, G.P. Sjoberg, X. Xie, and A. Wusatowska-Sarnek, eds., TMS, Warrendale, PA, 2014, pp. 67-77.

111. B.J. Bond, C.M. O'Brien, and J.L. Russell: in Superalloy 718 and Derivatives, E. Ott, A. Banik, J. Andersson, I. Dempster, T. Gabb, J. Groh, K. Heck, R. Helmink, X. Liu, and A. Wusatowska-Sarnek, eds., TMS, Warrendale, PA, 2014, pp. 107-18.

112. D.D. Krueger, R.D. Kissinger, and R.G. Menzies: Superalloys 1992, S.D. Antolovich and R. A. Mackay, eds., Warrendale, PA, 1992, pp. 277-86.

113. J.T. Cordy, S.L. Kelley, and L.W. Lherbier: 1984 Vacuum Metallurgy Conference on Specialty Metals Melting and Processing, G.K. Bhat and L.W. Lherbier, eds., TMS, PA, 1985, pp. 69-74.

114. S. Bashir and M.C. Thomas: J. Mater. Eng. Perform., 1993, vol. 2, pp. 545-50.

115. R. Rettig and R.F. Singer: Acta Mater., 2011, vol. 59, pp. 317-27.

116. B. Wang, F. Zhang, W. Cao, S. Chen, and S. Kou: Metall. Mater. Trans. A, 2015, vol. 46A, pp. 115-22.

117. Z. Guo, N. Saunders, J.P. Schillé, and A.P. Miodownik: Mater. Sci. Eng., A, 2009, vol. 499, pp. 7-13.

118. A.D. Patel, R.S. Minisandram, and D.G. Evans: Superalloys 2004, K.A. Green, T.M. Pollock, H. Harada, T.E. Howson, R.C. Reed, J.J. Schirra, and S. Walston, eds., TMS, Warrendale, PA, 2004, pp. 917-924.

119. K.M. Kelkar, S.V. Patankar, S.K. Srivatsa, R.S. Minisandram, D.G. Evans, J.J. Debarbadillo, R,H. Smith, R.C. Helmink, A. Mitchell, and H.A. Sizek: Proceedings of 2013 International Symposium on Liquid Metal Processing and Casting, M.J.M. Krane, A. Jardy, R. Williamson, and J. Beaman, eds., TMS, Warrendale, PA, 2013, pp. 3-12.

120. T.J. Watt, E.M. Taleff, F. Lopez, J. Beaman, and R. Williamson: Proceedings of 2013 International Symposium on Liquid Metal Processing and Casting, M.J.M. Krane, A. Jardy, R. Williamson, and J. Beaman, eds., TMS, Warrendale, PA, 2013, pp. 261-70.

121. U.S. Energy Information Administration: Annual Energy Outlook 2019 with Projections to 2050, 2019. DOE/EIA-0383 (2017). 
122. International Energy Agency: Global Energy \& $\mathrm{CO}_{2}$ Status Report 2018, 2018.

123. H. Hack, R. Purgert, and R. Schrecengost: in Joint EPRI-123HiMAT International Conference on Advances in High Temperature Materials, J. Shingledecker and M. Takeyama, eds., ASM International, Materials Park, OH, 2019, pp. 1476-86.

124. M. Fukuda, Y. Yagi, H. Fukutomi, S. Nishinoiri, K. Sato, T. Nishii, K. Nishimaki, T. Takano, H. Aoki, Y. Okuma, T. Furukawa, M. Shimada, N. Saito, K. Hashimoto, M. Kitamura, E. Saito, H. Semba, Y. Matsubara, K. Takahashi, T. Takahashi, and T. Suga: in Joint EPRI-123HiMAT International Conference on Advances in High Temperature Materials, J. Shingledecker and M. Takeyama, eds., ASM International, Materials Park, $\mathrm{OH}$ 2019, pp. 1487-99.

125. R. Viswanathan, J.F. Henry, J. Tanzosh, G. Stanko, J. Shingledecker, B. Vitalis, and R. Purgert: J. Mater. Eng. Perform. 2005, vol. 14, pp. 281-92, https://doi.org/10.1361 10599490524039.

126. S.A. David, J.A. Siefert, J.N. DuPont, and J.P. Shingledecker: Sci. Technol. Weld. Join., 2015, vol. 20, pp. 532-52, https:// doi.org/10.1179/1362171815Y.0000000035.

127. J.A. Siefert, J.P. Shingledecker, J.N. DuPont, and S.A. David: Sci. Technol. Weld. Join., 2016, vol. 21, pp. 397-427, https:// doi.org/10.1080/13621718.2016.1143708.

128. L.M. Pike: Ni-Cr-Co Alloy for Advanced Gas Turbine Engines, $8,066,938 \mathrm{~B} 2,2011$

129. R. Viswanathan, J. Hawk, R. Schwant, D. Saha, T. Totemeier, S. Goodstine, M. McNally, D.B. Allen, and R. Purgert: Steam Turbine Materials for Ultrasupercritical Coal Power Plants, Pittsburgh, PA, and Morgantown, WV, USA, Report 1081317 , 2009. https://doi.org/10.2172/1081317.

130. K.L. Kruger: Materials for Ultra-Supercritical and Advanced Ultra-Supercritical Power Plants, A. Di Gianfrancesco, ed., Woodhead Publishing, 2017, pp. 511-45. https://doi.org/10.101 6/b978-0-08-100552-1.00015-4.

131. R.A. Buckson and O.A. Ojo: Mater. Sci. Eng., A, 2012, vol. 555, pp. 63-70, https://doi.org/10.1016/j.msea.2012.06.034

132. K.A. Rozman, J.J. Kruzic, and J.A. Hawk: J. Mater. Eng. Perform., 2015, vol. 24, pp. 2841-46, https://doi.org/10.1007/s11665015-1588-9.

133. K.A. Rozman, J.J. Kruzic, J.S. Sears, and J.A. Hawk: J. Mater. Eng. Perform., 2015, vol. 24, pp. 3699-3707, https://doi.org/ 10.1007/s11665-015-1678-8.

134. R. Viswanathan, J. Shingledecker, J. Hawk, and S. Goodstine: Creep and Fracture in High Temperature Components-Design Life Assessment, 2nd Int. ECCC Conf., DEStech Publications, Inc., Lancaster, PA, 2009.

135. J. Shingledecker, R. Purgert, and P. Rawls: Advances in Materials Technology for Fossil Power Plants, Proceedings from the Seventh International Conference, ASM International, Materials Park, OH, 2014, pp. 41-52.

136. F. Abe: Engineering, 2015, vol. 1, pp. 211-24, https://doi.org/ 10.15302/J-ENG-2015031.

137. J. deBarbadillo, B. Baker, and X. Xie: in Superalloys 2016, M. Hardy, E. Huron, U. Glatzel, B. Griffin, B. Lewis, C. Rae, V. Seetharaman, and S. Tin, eds., Wiley, Hoboken, NJ, 2016, pp. 217-226. https://doi.org/10.1002/9781119075646.ch24.

138. R. Viswanathan, J. Shingledecker, and J.A. Hawk: Creep and Fracture in High Temperature Components-Design Life Assessment, 2nd Int. ECCC Conf., DEStech Publications, Inc., Lancaster, PA, 2009, pp. 31-43.

139. PCC Energy Group: Inconel® Alloy $740 \mathrm{H}$ : A Superalloy Specifically Designed for Advanced Ultra Supercritical Power Generation, 2014. http://www.specialmetals.com/files/PCCE G740HWhitePaper.pdf.

140. J.P. Shingledecker, N.D. Evans, and G.M. Pharr: Mater. Sci. Eng., A, 2013, vol. 578, pp. 277-86, https://doi.org/10.1016/ j.msea.2013.04.087.

141. S. Zhao, X. Xie, G.D. Smith, and S.J. Patel: Mater. Sci. Eng. A, 2003, vol. 355, pp. 96-105, https://doi.org/10.1016/S09215093(03)00051-0.

142. X. Xie, Y. Wu, C. Chi, and M. Zhang: in Superalloys, InTech, 2015, p. 13. https://doi.org/10.5772/61139.

143. Y. Wen, T. Cheng, P.D. Jablonski, J. Sears, and J.A. Hawk: Superalloy 718 and Derivatives, E. Ott, A. Banik, J. Andersson, I.
Dempster, T. Gabb, J. Groh, K. Heck, R. Helmink, X. Liu, and A. Wusatowska-Sarnek, eds., Wiley, Hoboken, NJ, 2014, pp. 361-378. https://doi.org/10.1002/9781119016854.ch29.

144. P.D. Jablonski, C.J. Cowen, and J.A. Hawk: in Superalloy 718 and Derivatives, E. Ott, J.R. Groh, A. Banik, I. Dempster, T.P. Gabb, R. Helmink, X. Liu, A. Mitchell, G.P. Sjoberg, X. Xie, and A. Wusatowska-Sarnek, eds., Wiley, Hoboken, NJ, 2010, pp. 617-628. https://doi.org/10.1002/9781118495223.ch48.

145. J.A. Hawk, T.-L. Cheng, J.S. Sears, P.D. Jablonski, and Y.-H. Wen: J. Mater. Eng. Perform., 2015, vol. 24, pp. 4171-81, https://doi.org/10.1007/s11665-015-1711-y.

146. L.M. Pike: in Superalloy 718 and Derivatives, E. Ott, J.R. Groh, A. Banik, I. Dempster, T.P. Gabb, R. Helmink, X. Liu, A. Mitchell, G.P. Sjoberg, X. Xie, and A. Wusatowska-Sarnek, eds., Wiley., Hoboken, NJ, 2010, pp. 645-660. https://doi.org/10.1002/ 9781118495223.ch50.

147. P.D. Jablonski and J.A. Hawk: J. Mater. Eng. Perform., 2017, vol. 26, pp. 4-13, https://doi.org/10.1007/s11665-016-2451-3.

148. S.J. Patel, J.J. De Barbadillo, B.A. Baker, and R.D. Gollihue: Procedia Eng., 2013, vol. 55, pp. 246-52, https://doi.org/10.1016/ j.proeng.2013.03.250.

149. J.J. De Barbadillo, R.D. Gollihue, B.A. Baker, J.J. De Barbadillo, B.A. Baker, and R.D. Gollihue: Proceeding of the 4th International Symposium - Supercritical CO2 Power Cycles, Pittsburgh, PA, 2014, pp. 1-15.

150. J.P. Shingledecker and G.M. Pharr: J. Mater. Eng. Perform., 2013, vol. 22, pp. 454-62, https://doi.org/10.1007/s11665-012$0274-4$.

151. R. Schwant, C. Shen, and M. Soare: Adv. Mater. Process., 2013, vol. 171 , pp. 18-22.

152. J. Andersson: in Superalloy 718 \& Derivatives: Energy, Aerospace, and Industrial Applications, E. Ott, X. Liu, J. Andersson, Z. Bi, K. Bockenstedt, I. Dempster, J. Groh, K. Heck, P. Jablonski, M. Kaplan, D. Nagahama, and C. Sudbrack, eds., Springer, Pittsburgh, PA, USA, 2018, pp. 899-916. https://doi.org/10.1007/9783-319-89480-5_60.

153. M. Prager and C.S. Shira: WRC Bull., 1968, vol. 128, pp. 1-55.

154. J.E. Franklin and W.F. Savage: Weld. J., 1974, vol. 53, pp. $380-387$

155. E.G. Thompson, S. Nunez, and M. Prager: Weld. J., 1968, vol. 47, pp. 299-313

156. D.S. Duvall and W.A. Owczarski: Weld. J., 1971, vol. 50, pp. 401-409.

157. T.F. Berry and W.P. Hughes: Weld. J., 1969, vol. 48, pp. 505-13.

158. J. Andersson: in Superalloy 718 and Derivatives, E. Ott, A. Banik, J. Andersson, I. Dempster, T. Gabb, J. Groh, K. Heck, R. Helmink, X. Liu, and A. Wusatowska-Sarnek, eds., Wiley, Hoboken, NJ, 2014, pp. 247-262. https://doi.org/10.1002/9781119016854.ch 21.

159. S.W. Banovic, J.N. DuPont, and A.R. Marder: Sci. Technol. Weld. Join., 2002, vol. 6, pp. 374-83, https://doi.org/10.1179/ 136217102225006804

160. J.C. Borland: Br. Weld. J., 1960, vol. 7, pp. 508-12.

161. J.N. DuPont, J.C. Lippold, and S.D. Kiser: Welding Metallurgy and Weldability of Nickel-Base Alloys, Wiley, Hoboken, NJ, 2009. https://doi.org/10.1002/9780470500262.

162. C. Huang and S. Kou: Weld. J., 2003, vol. 82, pp. 184-94.

163. G.A. Knorovsky, M.J. Cieslak, T.J. Headley, A.D. Romig, and W.F. Hammetter: Metall. Trans. A, 1989, vol. 20, pp. 2149-58, https://doi.org/10.1007/BF02650300.

164. F. Matsuda, H. Nakagawa, and K. Sorada: Trans. JWRI (Japanese Weld. Res. Institute), 1982, vol. 11, pp. 67-77.

165. M. Cieslak: Weld. J., 1991, vol. 70, pp. 49-56.

166. M.J. Cieslak, T.J. Headley, G.A. Knorovsky, A.D. Romig, and T. Kollie: Metall. Trans. A, 1990, vol. 21, pp. 479-88, https:// doi.org/10.1007/BF02782428.

167. M.J. Cieslak, T.J. Headley, A.D. Romig, and T. Kollie: Metall. Trans. A, 1988, vol. 19, pp. 2319-31, https://doi.org/10.1007/ BF02645056.

168. M.J. Cieslak, G.A. Knorovsky, T.J. Headley, and A.D. Romig: Metall. Trans. A, 1986, vol. 17, pp. 2107-16, https://doi.org/ 10.1007/BF02645909.

169. J.N. DuPont: Metall. Mater. Trans. A, 1996, vol. 27A, pp. 3612-20, https://doi.org/10.1007/BF02595452. 
170. J.N. DuPont, J.R. Michael, and B.D. Newbury: Weld. J., 1999, vol. 78, pp. 408-14.

171. J.N. Dupont, C.V. Robino, and A.R. Marder: Acta Mater., 1998, vol. 46, pp. 4781-90, https://doi.org/10.1016/S13596454(98)00123-2.

172. J.N. Dupont, C.V. Robino, J.R. Michael, R.E. Mizia, and D.B. Williams: Weld. J., 2004, vol. 83, pp. 289-300.

173. J. Andersson, S. Raza, A. Eliasson and K.B. Surreddi: Superalloy 718 and Derivatives, E. Ott, A. Banik, J. Andersson, I. Dempster, T. Gabb, J. Groh, K. Heck, R. Helmink, X. Liu, A. Wusatowska-Sarnek, eds., John Wiley \& Sons, Inc., Hoboken, NJ, USA, 2014, pp. 181-192. https://doi.org/10.1002/9781119016854 .ch 15.

174. J.L. Robinson and M.H. Scott: Philos. Trans. R. Soc. A Math. Phys. Eng. Sci., 1980, vol. 295, pp. 105-17. https://doi.org/10. 1098/rsta.1980.0079.

175. W.F. Savage, E.F. Nippes, and G.M. Goodwin: Weld. J., 1977, vol. 56 , pp. $245-53$.

176. S. Singh, W. Fransson, J. Andersson, A. Brederholm, and H. Hänninen: Superalloy 718 \& Derivatives: Energy, Aerospace, and Industrial Applications, E. Ott, X. Liu, J. Andersson, Z. Bi, K. Bockenstedt, I. Dempster, J. Groh, K. Heck, P. Jablonski, M. Kaplan, D. Nagahama, and C. Sudbrack, eds., Springer, Pittsburgh, PA, 2018, pp. 929-37. https://doi.org/10.1007/978-3-31989480-5_62.

177. R.G. Thompson, J.R. Dobbs, and D.E. Mayo: Weld. J., 1986, vol. 65, pp. 299-304.

178. R. Vincent: Acta Metall., 1985, vol. 33, pp. 1205-16, https:// doi.org/10.1016/0001-6160(85)90231-7.

179. K. Vishwakarma: Microstructural Analysis of Weld Cracking in 718 Plus Superalloy, University of Manitoba, Winnipeg, 2007.

180. W. Chen, M.C. Chaturvedi, and N.L. Richards: Metall. Mater. Trans. A, 2001, vol. 32A, pp. 931-39, https://doi.org/10.1007/ s11661-001-0350-0.

181. F. Hanning and J. Andersson: Superalloy 718 \& Derivatives: Energy, Aerospace, and Industrial Applications, E. Ott, X. Liu, J. Andersson, Z. Bi, K. Bockenstedt, I. Dempster, J. Groh, K. Heck, P. Jablonski, M. Kaplan, D. Nagahama and C. Sudbrack, eds., Springer, Pittsburgh, PA, 2018, pp. 917-928. https://doi.org/ 10.1007/978-3-319-89480-5 61.

182. S. Kou: Welding Metallurgy, Wiley, Hoboken, NJ, 2002. https://doi.org/10.1002/0471434027.

183. Z. Li, S.L. Gobbi, and J.H. Loreau: J. Mater. Process. Technol., 1997, vol. 65, pp. 183-90, https://doi.org/10.1016/S09240136(96)02260-1.

184. W.A. Owczarski, D.S. Duvall, and C.P. Sullivan: Weld. J., 1966, vol. 45, pp. 145-55.

185. J.J. Pepe and W.F. Savage: Weld. J., 1967, vol. 46, pp. 411-22.

186. M. Qian and J.C. Lippold: Weld. J., 2002, vol. 81, pp. 233-38.

187. N.L. Richards and M.C. Chaturvedi: Int. Mater. Rev., 2000, vol. 45, pp. 109-29, https://doi.org/10.1179/ 095066000101528331.

188. M. Prager and C.S. Shira: Welding of Precipitation-Hardening Nickel-Base Alloys, Bulletin, Welding Research Council (U.S.), 1968.

189. S.A. David, J.A. Siefert, J.N. Dupont, and J.P. Shingledecker: Sci. Technol. Weld. Join., 2015, vol. 1718, pp. 532-52, https:// doi.org/10.1179/1362171815Y.0000000035.

190. R. Viswanathan, J. Sarver, and J.M. Tanzosh: J. Mater. Eng. Perform., 2006, vol. 15, pp. 255-74, https://doi.org/10.1361/ $105994906 \mathrm{X} 108756$.

191. J.A. Hawk: NiCrMoCb Alloy with Improved Mechanical Properties, US 8,101,122 B2, 2012.

192. R. Cozar and A. Pineau: Metall. Trans., 1973, vol. 4, pp. 47-59.

193. A.J. Detor, R. DiDomizio, R. Sharghi-Moshtaghin, N. Zhou, R. Shi, Y. Wang, D.P. McAllister, and M.J. Mills: Metall. Mater. Trans. A, 2018, vol. 49A, pp. 708-17, https://doi.org/10.1007/ s11661-017-4356-7.

194. R. Shi, D.P. McAllister, N. Zhou, A.J. Detor, R. DiDomizio, M.J. Mills, and Y. Wang: Acta Mater., 2019, vol. 164, pp. 220-36, https://doi.org/10.1016/j.actamat.2018.10.028.

Publisher's Note Springer Nature remains neutral with regard to jurisdictional claims in published maps and institutional affiliations. 